\title{
Revisão das espécies brasileiras do gênero Rheedia L. (Guttiferae) (*)
}

\author{
Maria Elisabeth van den Berg (*t)
}

\section{Resumo}

Estudo taxonômico do gênero Rheedia L. no Brasil. São apresentados: histórico, descrição do gênero, secções e oito espécies brasileiras, chave para separação entre as mesmas, sua sinonímia, distribuição geográfica e comentários críticos. Apresenta diagnose detalhada de $\mathbf{R}$. albuquerquei van den Berg, endêmica na bacia do rio Negro, recentemente publicada em nota prévia. Inclui ilustrações de todas as espécies.

\section{INTRODUÇÃo}

Um dos primeiros gêneros de Guttiferae a ser classificado foi Rheedia L., que compreende cerca de 30 espécies mal definidas, em razão dos poucos trabalhơs existentes, esparsos e sem continuidade. A última revisão sobre o gênero fơ realizada em meados do século XIX por Planchon \& Triana (1860) e apresenta várias lacunas.

A distribuição geográfica do gênero Rheedia está restrita à América do Sul, América Central e Madagascar.

A maioria das espécies de Rheedia apresenta frutos édulos, geralmente com sabor ácido e um tanto adstringente. Algumas dessas espécies são cultivadas e outras são encontradas apenas em estado silvestre, sendo designadas pelo nome vulgar de "bacuri-pari".

O estudo de frutas para aproveitamento alimentar, ao natural e sob a forma de conservas (compotas, geléias, sucos concentrados e liofilizados), está se tornando cada vez mais importante para obtenção de novas formas de nutrientes. Neste particular, o gênero Rheedia pode oferecer excelente material.
$\mathrm{Na}$ Amazônia Oriental uma das espécies comumente cultivada, em sítios e quintais, é Rheedia macrophylla (Martius) Planchon et Triana, um dos poucos "bacuri-pari" a sofrer comercialização ('), embora em escala reduzida. Esta espécie foi objeto de uma pesquisa tecnológica feita pelo $\mathrm{Dr}$. Owao Nagata $\left({ }^{2}\right)$ que, gentilmente, nos cedeu alguns dados obtidos na análise desta fruta. $O$ quadro abaixo permite aquilatar o seu valor industrial :

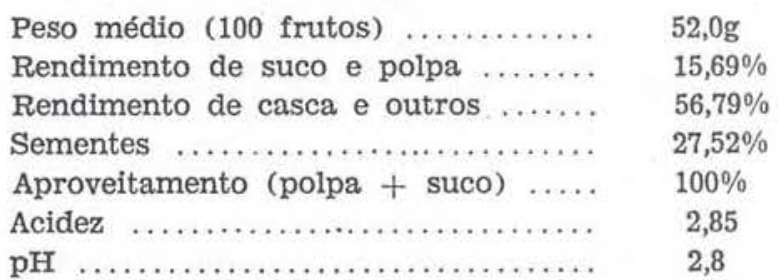

Solidos solúveis (açúcares,

ácidos, etc.) $\ldots \ldots \ldots \ldots \ldots \ldots \ldots \ldots \mathrm{BX}^{\circ} 14,2 \%$

Amino ácidos (nitrogenados) .... $6,39 \mathrm{mg} / 00$

Açúcares reduzidos .............. $20,8 \%$

Sólidos totais . . . . . $18,46 \ldots \ldots \ldots \ldots \ldots \ldots$

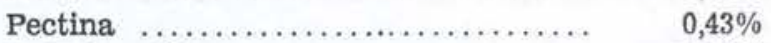

Extrato etéreo ..................... $0,54 \%$

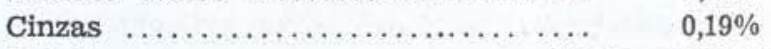

Sabor ...................... Forte, agradável.

Este trabalho visa a contribuir para o meIhor conhecimento das Rheedia por se tratar de um gênero representativo da flora brasileira e cơm centro de dispersão na Amazônia, há muito necessitando de uma revisão sob o ponto de vista taxonômico.

\section{REVISÃo BIBLIOGRÁFICA}

Plumier (1703) foi o primeiro autor a descrever uma espécie do gênero Rheedia, com o nome de Van Rheedia. Em Linnaeus (1735) há

(") - Parte deste trabalho foi apresentada sob o título "O gênero Reedhia L. (Guttiferae) na Amazônia Brasileira", e aprovada, como tese de Mestrado perante a Universidade de Säo Paulo, em 1975.

("*) - Museu Paraense Emílio Goeldi, Belém.

(1) - Em Manaus, esporadicamente, sẫo encontradas em pequenas quantidades, na feira, R. madruno (H. B. K.) Planchon et Triana e R. brasiliensis (Martius) Planchon et Triana.

(2) - Químico (Univ. Tóquio), pesquisador de uma empresa japonesa e colaborador eventual do CPATU/EMBRAPA (1975). 
uma citação com este nome. Plumier (1755-60), numa reedição ilustrada por Burmanier, apresenta uma curta descrição e uma figura do hábito de uma planta sob o título geral de Van Rheedia. Esta planta, provavelmente é Rheedia lateriflora, descrita por Linnaeus (1753), e que é.a "species-typus" para o gênero Riheedia. Este deve ser citado como de autoria unicamente de Linnaeus (Rheedia L.), de acordo com as Regras Internacionais de Nomenclatura Botânica (Staffleu et al., 1972), uma vez que foi descrito formalmente por aquele autor sob o epiteto genérico Rheedia em maio de 1753 , quando se iniciou a validade dos nomes genéricos e específicos.

Aublet (1775) foi um dos primeiros autores a aceitar o novo gênero e, em sua obra cita Linnaeus e também Plumier.

Primitivamente, várias espécies do gênero Rheedia foram descritas e classificadas sob outros gêneros. Desses, alguns já existiam, como Garcinia Martius (1841), adotado por Miquel (1850). Outros, eram gêneros novos como, por exemplo, Verticillaria Ruiz et Pavon (1794), Chloromyron Persoon (1807) e Lamprophyllum Miers (1853), criacios por esses autores para enquadrar diversas espécies de Rheedia.

Choisy (1824) citou a espécie Rheedia lateriflora L. como duvidosa ou pouco conhecida, adotando o mesmo critério em relação ao gênero Chloromyron Persoon, ao qual, subordinou Verticillaria Ruiz et Pavon, como sinônimo. Porém, em 1849, Choisy descreveu Rneedia sieberi, ratificando, portanto, a validade desse gênero, embora na mesma obra, cite outra espécie de Rheedia como Garcinia macrophylla. Aliás, Choisy incorreu no mesmo erro de Bentham (1843) que se referiu a Garcinia macrophylla relacionando material que na realidade é de Rheedia benthamiana. Engler (1888) repetiu o mesmo engano, o que será discutido mais adiante.

Ainda em 1824, Choisy propôs a divisão de Guttiferae em tribos, entre as quais Garcinieae à qual Rheedia está subordinada.

Planchon \& Triana (1860) fizeram a primeira revisão sobre o gênero Rheedia, o qual dividiram em duas secções: 1) Eurheedia, compreendendo as espécies portadoras de frutos lisos e, 2) Verticillaria Ruiz et Pavon, englobando as espécies com frutos verrucoso-muricados. Segundo Planchon \& Triana, as espécies anteriormente descritas sob o gênero Verticillaria Ruiz \& Pavon (1794) e, parcialmente sob Calophyllum por Humboldt, Bonpland \& Kunth (1821), deveriam ser enquadradas nesta última secção.

Entretanto, na mesma obra (1860), Planchon \& Triana descreveram seis espécies novas e se referiram à contestada $R$. floribunda, em separado, numa secção dúbia, por ignorarem o tipo do fruto desta espécie.

Engler (1888), fez a primeira e única revisão das espécies brasileiras de Rheedia, na qual ratifica as secções e várias espécies descritas por Planchon \& Triana. Engler apontou oito espécies válidas para o Brasil: $R$. macrophylla, $R$. longifolia, $R$. brasiliensis, $R$. caliptrata, R. gardneriana, R. spruceana e $R$. floribunda, sendo apenas esta última enquadrada na secção Verticillaria. Para a Amazônia Brasileira, Engler relacionou apenas quatro espécies, cuja validade será discutida mais adiante. Nesse trabalho, Engler descreveu três espécies e três variedades novas, das quais, uma espécie e uma variedade eram originárias da Amazônia. Embora o objetivo de Engler fosse a Flora do Brasil, ele incluiu uma nova espécie guianense em seu trabalho: $R$. sagotiana, cuja validade igualmente é discutivel.

Em sua posterior monografia sobre Guttiferae, Engler (1895), aceita para o gênero Rheedia 17 espécies válidas (15 na América tropical e 2 em Madagascar), distribuidas em três secções: Eurheedia Planchon et Triana, Ruscoides Vesque e Verticillaria Ruiz et Pavon.

Em 1889, Vesque propôs uma nova combinação, baseada em um nome manuscrito por Miers - Verticillaria rostrata - cujo "typus" se encontrava no Museu de Paris.

Vesque (1893) ao escrever o capítulo referente a Guttiferae, pôs em discussão a validade de $R$. floribunda; que considerou apenas uma variedade de $R$. acuminata.

No século XIX, entre os autores brasileiros poucas referências são encontradas, exceto Barbosa Rodrigues (1894), em cuja obra há informações sobre a origem dos nomes científicos, nomes vulgares, aspecto geral e tipos 
de frutos de Rheedia brasiliensis, R. gardneriana e $R$. macrophylla.

Chodat \& Hassler (1903) encontraram no Paraguai $R$. brasiliensis, para a qual descreveram uma nova variedade: Rheedia brasiliensis (Martius) Planchon et Triana var. salicifolia.

Em trabalho apresentado como tese e posteriormente publicado, Pulle (1906) enumera para o Suriname $R$. macrophylla e $R$. floribunda, fazendo alusão à sua distribuição na Bacia Amazônica.

Pittier (1912) em um ensaio sobre as plantas da Colômbia e América Central, descreveu duas espécies novas de Rheedia ( $R$. intermedia e $R$. magnifolia), redescreveu $R$. edulis Planchon et Triana e $R$. madruno Planchon et Triana, propondo para esta, duas variedades novas: $R$. madruno var. ovata e $R$. madruno var bituberculata.

Eyma (1932), em suas notas críticas a respeito da Flora Surinamense, teceu uma série de considerações sobre a validade e o relacionamento de várias Rheedia, além de descrever uma nova espécie, cuja legitimidade é comentada no capítulo referente a $R$. acuminata.

Em seu manual de plantas úteis da Amazônia, Le Cointe (1947) destacou apenas Rheedia macrophylla como de utilidade, indicando as localidades onde comumente é encontrada, o uso restrito de sua madeira e referindo-se aos frutos comestiveis dessa e das demais espécies de Rheedia. O mesmo autor mencionou ainda o fornecimento de uma amêndoa oleaginosa por R. macrophylla.

Standley \& Williams (1961) apontam para o gênero Rheedia 40 espécies, das quais 4 em Madagascar e as restantes na América Tropical. Para a Guatemala, eles citaram 3 espécies: R. edulis, R. intermedia e R. macrantha. Esta última havia sido descrita em 1944 por Standley \& Steyermark.

Lindemann \& Mennega (1963), no seu tratado sobre as árvores e madeiras do Suriname, fizeram referência a três espécies, Rheedia benthamiana, R. macrophylla e R. kappleri (também encontradas na Amazônia) informando que elas são vulgarmente conhecidas como "pakoeli", sendo que $R$. kappleri ( $=R$. acuminata) tem ainda o nome local de "swampoe- pakoeli". Estes autores, além de uma descriçāo geral dessas espécies e seu hábito, fizeram menção à tonalidade de sua madeira: em Rheedia benthamiana, vermelho-arroxeada; amarelada com pequenas manchas alaranjadas em $R$. kappleri e, avermelhada no centro, esbranquiçando para a periferia, em $R$. macrophylla.

Melchior (1964) é da opinião que existem 30 espécies válidas de Rheedia, todas tropicais. Porém, segunda Willis (1973), existem 45 espécies válidas de Rheedia, distribuídas pela América do Sul, América Central, Indias Ocidentais e Madagascar.

Cavalcante (1972) citou apenas R. macrophylla ("bacuripari") e $R$. benthamiana ("bacuripari selvagem"), como sendo comestíveis.

Mariz (1975) em seu trabalho sobre as Guttiferae de Pernambuco, relacionou para aquele Estado apenas Rheedia gardneriana, devendo serem adicionadas $R$. macrophylla e $R$. brasiliensis, como ocorrências novas para aquele Estado.

Machado (1954) refere-se à presença de uma Rheedia sp. arbustiva encontrada às margens do Araguaia e Tapirapés.

Esta espécie, produtora de frutos amarelos e comestíveis, muito procurados pelas crianças e conhecida como "azedinha" é denominada "Rrú-uaré-anin" pelos Carajás.

Para o Paraná, apenas Angely (1965) cita duas espécies: $R$. gardneriana e $R$. macrophylla.

Para o extremo oeste de Santa Catarina e o noroeste de R. Grande do Sul, Klein (1972) cita a ocorrência nova de $R$. gardneriana.

Rambo (1954) cita $R$. gardneriana como ocorrente na selva pluvial dos arredores de Porto Alegre e estabelece que as espécies existentes nesta selva são irradiações da selva higrófila do Brasil Central e da Amazônia, daí haver uma explicação para a presença de espécies amazônicas '(entre as quais $R$. gardne riana) no Rio Grande do Sul.

Rambo (1954) cita esta mesma espécie integrando a flora fanerogâmica de Porto Alegre e ocorrendo desde o Ceará até o Rio Grande do Sul, ao que deve ser acrescido que ocorre também na Amazônia. 
Para o litoral sul, ainda Rambo (1954), localiza $R$. gardneriana em Sombrio (SC) e às proximidades da Fazenda do Ãrroio, no km 125 da rodovia Osório-Tamandaré (RS). Rambo veio assim suprir a ausência de citações de Rheedia para a vegetação do Rio Grande do Sul o que não tira o valor da notável obra de Lindman (1906), mas a complementa.

\section{MATERIAL E MÉTODOS}

As observações e conclusões abtidas neste trabalho basearam-se principalmente em exsicatas (material herborizado) e fotótipos provenientes, por empréstimo, dos seguintes herbários :

- Museu Paraense Emílio Goeidi (MG), Belém-PA

- Instituto Nacional de Pesquisas da Amazônia (INPA), Manaus-AM

- Centro de Pesquisa Agropecuária do Trópico Úmido (IAN), Belém-PA

- Museu Nacional (R) - Rio de Janeiro - RJ

- Jardim Botânico do Rio de Janeiro (RB)

- Instituto de Botânica de São Paulo (SP)

- Departamento de Botânica do Instituto de Biociências da USP (SPF)

- Departamento de Botânica da Universidade Federal de Pernambuco (U.F.Pe.), Recife-PE.

Também foram realizadas observações e coletas no campo, sendo que o material obtido está registrado no herbário $M G$ sob a forma de exsicatas ou preservado (fixado) em FAA $(90 \mathrm{ml}$ de álcool etílico a $50 \%, 5 \mathrm{ml}$ de formol a $40 \%$ e $5 \mathrm{ml}$ de ácido acético glacial puro) para flores, frutos e fragmentos de folhas.

Foi seguida a metodologia usualmente seguida em estudos de Taxonomia Vegetal: revisão bibliográfica, análise, descrição e mensuração de material, estudo da sinonímia, distri. buição geográfica, elaboração de comentários críticos e dados adicionais.

Para a descrição e tomada de medidas florais foram usados botōes em estado de préântese.

As siglas de herbário citadas ao longo do trabalho estão de acordo com Lanjouw \& Stafleu (1959).
TRATAMENTO SISTEMÁtico DO GÊNERO RHEEDIA L. NO BRASIL

Rheedia L. Sp. Plant. ed. I. 2: 1193. 1753.

Verticillaria Ruiz et Pavon Prodr. Fl. Peruv. $4: 81$, tab. 15. 1794 .

Chloromyron Persoon Syn. Pl. 2: 73. 1807. Lamprophyllum Miers in Trans. Linn. Soc. 21 : 249, tab. 26. 1853. "pro parte".

Árvores de $5-20 \mathrm{~m}$ de altura, ramos cilindricos, retos, resinosos. Folhas opostas, de tamanho variável, pecíolos conspícuos, sulcados longitudinalmente e rugosos transversalmente; lâmina coriácea ou subcoriácea, raro membranácea, elíptica, elíptico-oblonga, elíptico-oval, elíptico lanceolada ou obovada; costa supra $\epsilon$ infra proeminente, nervos laterais numerosos. conspícuos em ambas as faces, anastomosando-se sob a margem, reticulação conspícua. Inflorescências axilares (raro caulinares), fasciculares, sendo as masculinas e raro as hermafroditas, inseridas sobre um pulvínulo. Flores polígamo-dióicas: duas sépalas, coriáceas, conatas na base; quatro pétalas, carnosas ou membranáceas, decussadas, externamente alternas com as sépalas, reflexas após a ântese; prefloração imbricada. Flores masculinas: estames livres numerosos (de 20-30), bisseriados, inseridos quase sempre inferiormente ao disco central crasso, filetes lineares engrossando em direção à base, conectivos insignificantes, ânteras dorsifixas, subglobosas, tecas ovaliformes, deiscência rimosa, obliquo-longitudinal, rudimento do ovário pouco conspícuo. Flores hermafroditas: pedicelos mais grossos (ca. de $1 \mathrm{~mm}$ de diâmetro), que as das flores masculinas $(0,7 \mathrm{~mm}$ de diâmetro); sépalas $\mathrm{e}$ pétalas semelhantes às das flores masculinas, estarnes menos numerosos (de 10-16), unisseriacios, inseridos abaixo do ginóforo (discóide), crasso e dilatado, medianamente deprimido e sobre o qual está assentado o ovário 3-locular, ou por aborto, 2-1 locular, lóculos uniovulados, óvulo anfítropo, micrópila inferior, estilete curto e crasso, estigma caliptriforme, convexo, levemente lobado ou fendido na margem. Fruto: baga, epicarpo coriáceo. liso ou muricado, com 3 a 1 sementes cilindráceas, albuminadas, envolvidas por um arilo branco-amarelado, afixas medianamente; embrião com cotilédones obsoletos. 
As espécies brasileiras do gênero Rheedia estão divididas em duas secções distintas, divisão esta, baseada no aspecto exterior de seus frutos.

1. Secção Rheedia Planchon et Triana

Frutos com epicarpo liso:
R. longifolia
R. macrophylla
R. gardneriana
R. brasiliensis
R. albuquerquei

II. Secção Verticillaria Ruiz et Pavon.

Frutos com epicarpo muricado-tuberculado:
R. acuminata
R. benthamiana
R. madruno

Embora Engler (1888) tenha indicado também oito espécies para o Brasil, (R. macrophylla, R. longifolia, $R$. brasiliensis, $R$. calyptrata, $R$. gardneriana, $R$. spruceana, $R$. tenuifolia e $R$. floribunda), verificamos que apenas quatro ainda são válidas, devendo as restantes serem consideradas sinônimos de diversas outras espécies de Rheedia, adiante estudadas.

No que se refere à Amazônia Brasileira, ainda de acordo com Engler (1888), existiriam ali somente quatio Rheedia (R. macrophylla, $R$. longifolia, R. spruceana e $R$. floribunda), das quais só as duas primeiras ainda continuam válidas. Na realidade, todas as oito espécies brasileiras ocorrem nesta região, sendo que três ( $R$. acuminata, $R$. benthamiana e R. madruno) são nativas da Amazônia e duas outras constituem endemismos ( $R$. longifolia e $R$. albuquerquei).

As espécies brasileiras do gênero Rheedia são comumente designacias por "bacuri-pari", "bacupari" ou ainda "bacopari", sem embargo de existirem muitas variantes e outros nomes locais ou específicos, mencionados neste trabalho para cada espécie em particular.

$\mathrm{O}$ vocábulo "bacuripari" origina-se indiscutivelmente do "nhééngatu" $\left({ }^{3}\right)$ "uakuripa'ri . que segundo verificamos em Sampaio (1955), Barbosa Rodrigues (1905) e Stradelli (1928) significa "bacuri-de-cerca", literalmente "o fruto (ua) apressado (curi), temporão, de cerca (pari). Na verdade há uma grande semelhança entre o legítimo "bacuri" (Platonia insignis Martius) e o "bacuri pari" Rheedia spp.) e, os frutos das espécies de ambos os gêneros amadurecem rapidamente, comprovando o agudo senso de observação e propriedade do indígena brasileiro.

Para a perfeita separação entre as espécies brasileiras de Rheedia, predomina o caráter "fruto", tal como acontece nas Leguminosae em geral. Daí apresentar este trabalho uma chave de separação baseảda principalmente neste caráter, acrescida de informações adicionais sobre aspectos florais ou vegetativos.

\section{CHAVE PARA A SEPARAÇÃO DAS ESPÉCIES DE RHEEDIA ENCONTRADAS NO BRASIL}

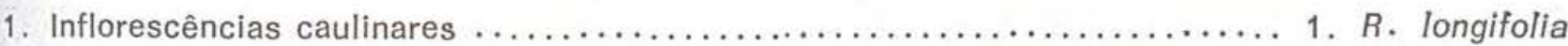

1. Inflorescências axilares

2. Râmulos com secção transversal fortemente poliédrica com as faces de-

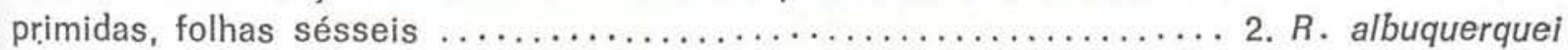

2. Râmulos com secção transversal circular ou elipsóide, folhas pecioladas.

3. Frutos com epicarpo liso

\section{Frutos rostrados}

5. Frutos com comprimento e diârnetro superiores a 5 e $4 \mathrm{~cm}$,

(3) - Segundo Barbosa Rodrigues (1903), deve ser usado este vocábulo para designar a língua geral dos indígenas e, não "tupi" que tem origem num termo pejorativo. 
5. Frutos com comprimento e diâmetro nunca alcançando $4,5 \mathrm{e}$

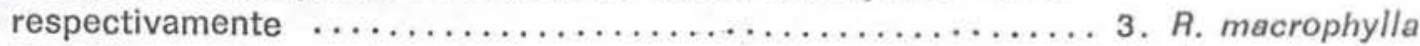
$2,8 \mathrm{~cm}$ respectivamente $\ldots \ldots \ldots \ldots \ldots \ldots \ldots \ldots \ldots \ldots \ldots \ldots \ldots \ldots \ldots \ldots \ldots \ldots \ldots$, R. gardneriana

4. Frutos sem rostro $\ldots \ldots \ldots \ldots \ldots \ldots \ldots \ldots \ldots \ldots \ldots \ldots \ldots \ldots \ldots \ldots, R$, brasiliensis

3. Frutos com epicarpo verrucoso-muricado

6. Frutos rostrados, flores com estigma profundamente inciso ......6. R. acuminata

6. Frutos sem rostro, flores com estigma lobado

7. Frutos com superfície reticulada, com comprimento e diâmetro

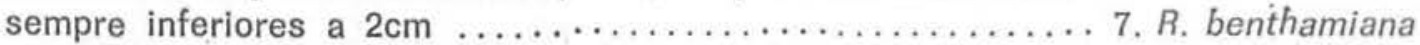

7. Frutos muricados com comprimento e diâmetro sempre superiores a $4 \mathrm{~cm}$ 8 R. madruno

1. Rheedia longifolia Planchon et Triana, Ann. Sci. Nat. 4e. sér. 14:322. 1860.

TYPUS: BRASIL: "Prov. Alto Amazonas, prope Panuré ad Rio Uaupés", X - 1853-I-1854; R. Spruce 2441 (holotypus $\mathrm{K}$, isotypus MG!).

Árvore de $6-12 \mathrm{~m}$ (até $20 \mathrm{~m}$ ) de altura e $10-15 \mathrm{~cm}$ (até $25 \mathrm{~cm}$ ) de diâmetro. Râmulos cilíndricos, grossos, com $7-8 \mathrm{~mm}$ de diâmetro, gemas foliares conspícuas. Folhas: pecíolo alongado, de $25-40 \mathrm{~mm}$ de comprimento a 4-6mm de diâmetro, achatado, tetrágono, profundamente canaliculado em direção à nervura central, sulcado longitudinalmente e rugoso transversalmente: lâmina de $27-38 \mathrm{~cm}$ de comprimento e $7,5-11 \mathrm{~cm}$ de largura, brilhosa na face ventral e opaca, nigropunctulada na face dorsal, coriácea, lanceolada ou oblongo-lanceolada, base atenuada, ápice agudo, margem estreitamente revoluta, pouco ondulada; costa supra e infraproeminente e sulcada, nervação secundária semi-imersa, mais ou menos paralela e distanciada de $3-10 \mathrm{~mm}$ da margem, sob a qual há uma reticulação perceptível em ambas as faces. Inflorescências caulifloras, com botões florais pequenos em relação às outras espécies, ovaliformes, com ápice pontiagudo, pedúnculos de $4-10 \mathrm{~mm}$. Flores masculinas: 15-30 em cada fascículo, este congesto; sépalas esverdeadas, ovóides, com $2 \mathrm{~mm}$ de altura e $3 \mathrm{~mm}$ de largura, pétalas esbranquiçadas obovadas, com $3,5-4 \mathrm{~mm}$ de altura e $2,5-3 \mathrm{~mm}$ de largura, reflexas após a ântese; estames de 25-30. Flores hermafroditas: $3-5$ por fascículo, disco com $1-1,5 \mathrm{~mm}$ de altura e $3 \mathrm{~mm}$ de diâmetro, longitudinalmente sulcado, ovário ovóide, com $3-4 \mathrm{~mm}$ de altura e $3 \mathrm{~mm}$ de diâmetro, coroacio por um estígma caliptriforme, com $1 \mathrm{~mm}$ de altura e $2,5 \mathrm{~mm}$ de diâmetro. Fruto: liso, ama:elo esverdeado, opaco, oboval com $2-2,5 \mathrm{~cm}$ de comprimento e $1,5-1,8 \mathrm{~cm}$ de diâmetro, rostro ausente, resto do estígma persistente, base estreitando-se em direção ao pedúnculo, portando restos do perianto e do androceu.

Floresce de maio a julho e frutifica de jutho a setembro.

MATERIAL ESTUDADO E DISTRIBUIÇÃO GEOGRÁFICA :

BRASIL: estado do amazonas: Rio Capitari, Codajás, 31-VIII-1950, R. L. Fróes 26460 (IAN). Humaitá; 24-IX-1973, J. M. Pires \& N. A. Rosa 13279 (IAN). - Lábrea, rio Purus, rio Ituxi, rio Curuquetê. "vicinity of cachoeira Santo Antônio, 15-VII-1971, G. T. Prance et al. 14248 (MG, INPA).

ESTADO DO ACRE: Cruzeiro do Sul, Estrada Alemanha, 7-V-1971, P. J. M. Maas et al. P12759 (INPA).

TERRITÓRIO FEDERAL DE RONDÔNIA: "ROad to cassiterita mines in Serra dos Três Irmãos, north bank of rio Madeira, $8 \mathrm{~km}$ above Mutumparaná"; 5-VII-1968, G. T. Prance et al. 5649 (MG, INPA).

MATERIAL ADICIONAL :

BOLIVIA ESTADO PANDO: "West bank of rio Madieira, $12 \mathrm{~km}$ above Abunã"; 20-VII-1968, G. T. Prance et al. 6320 (MG INPA). 


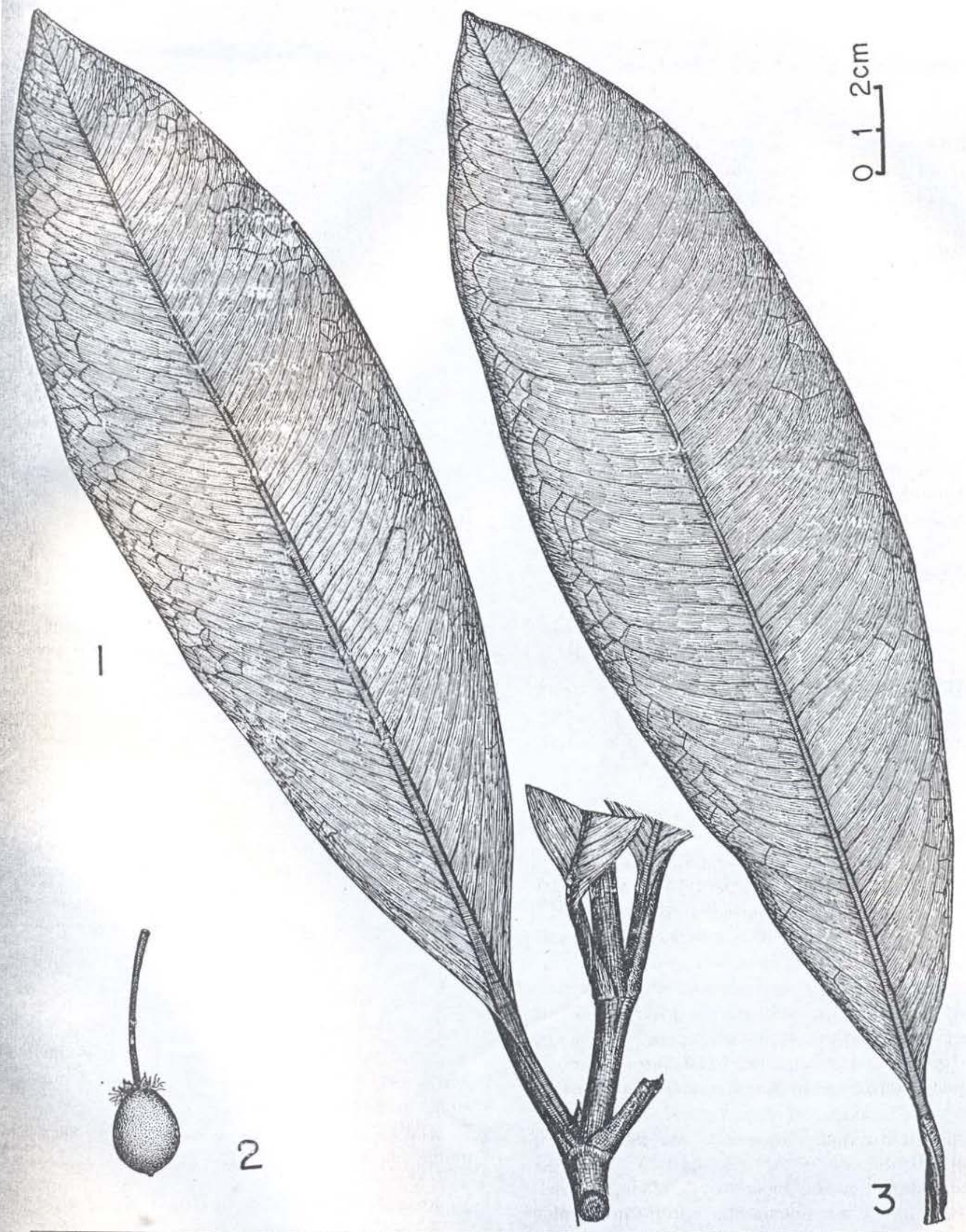

Est. 1 - R. longifolia: Fig. 1 - ramo foliar em face ventral (G. T. Prance et al, 14248); Fig. 2 - fruto (idem); Fig. 3 - ramo foliar em face dorsal (Spruce 2441). 
É curioso que Engler (1888) tenha acertado quando enquadrou $R$. longifolia na secção Eurheedia, sem, no entanto, conhecer os seus frutos. Planchon et Triana (1860), autores dessa espécie, haviam preferido deixá-la à parte, com a nota "species, ob fructus ignotos, quoad sectionem dubiae".

Rheedia longifolia é uma das espécies menos conhecidas de "bacuri-pari" e também das mais distintas por apresentar o fenômeno da caulifloria.

Suas grandes folhas coriáceas dotadas de um forte pecíolo tetrágono e nervação semiimersa a tornam inconfundivel.

Seus frutos assemelham-se aos de $R$. brasiliensis.

Esta espécie se restringe à Amazônia Ocidental, sendo endêmica na região compreendida entre as bacias dos rios Purus e Madeiıa-Mamoré.

Habita as matas de terra firme, sobre solos arenosos (geralmente latossolos).

2. Rheedia albuquerquei van den Berg, Acta Amaz. 5(3): 285. 1975.

TYPUS: BRASIL: E. DO AMAZONAS, Rio Negro, Ilha Gavião, "near mouth of Rio Branco"; 05-VII/12-VIII/1967; R. E. Schultes 24535 (holotypus INPA!, isotypus IAN!).

Árvore de $5-12 \mathrm{~m}$ de altura e $10-15 \mathrm{~cm}$ de diâmetro, exsudando resina variando da cor creme a amarelo esverdeado. Râmulos com nós deltóides e entrenós de $2,5-4 \mathrm{~cm}$ de comprimento, marrom acinzentados, glabros, muito angulosos, com os lados côncavos, acentuando-se esses caracteres em direção ao ápice em cuja extremidade apresentam três ramificações, dando impressão de se tratar de longos pecíolos. Folhas: sésseis, com lâmina de $7-16,5 \mathrm{~cm}$ de comprimento e $2-8,5 \mathrm{~cm}$ de largura, opaca (raro semi-brilhosa) e, parda ou marrom escura "in sicco" na face ventral; opaca e castanho-acinzentada "in sicco", na face dorsal; fortemente coriácea, assimétrica, oblongoelíptica ou ovada, base arredondada, assimétrica, às vezes levemente cordiforme, ápice obtuso ou emarginado, margem lisa, ondulada, levemente revoluta; costa supra proeminente, infra extremamente proeminente larga $(3 \mathrm{~mm})$ e alta $(3 \mathrm{~mm})$ na base, estreitando-se lentamente em direção ao ápice e apresentando uma secção triangular aguda, nervação semiimersa, nervuras secundárias irregularmente paralelas, distanciadas de 1,5 a $3,5 \mathrm{~mm}$ entre si, geralmente bipartindo-se a cerca de $8 \mathrm{~mm}$ abaixo da margem, reticulação "in sicco" perceptivel em ambas as faces. Inflorescências axilares situadas sobre um pulvínulo conspicuo com $7-12 \mathrm{~mm}$ de diâmetro e $3-4 \mathrm{~mm}$ de altura. Flores não vistas. Fruto liso, alaranjado tendendo a vermelho ou amarelo forte quando maduro, muito brilhoso, elipsóide (levemente rostrado quando jovem) ou arredondado, assimétrico, com $2,2-3 \mathrm{~cm}$ de comprimento e $1,3-2,5 \mathrm{~cm}$ de diâmetro, restos do estigma persistente, base arredondada ou estreitando-se em direção aơ pedúnculo, portando resquícios do perianto e androceu. Sementes fusiformes com ca. $1,5 \mathrm{~cm}$ de comprimento e $0,8 \mathrm{~cm}$ de diâmetro.

\section{MATERIAL ESTUDADO E DISTRIBUIÇÃo} GEOGRÁFICA:

BRASIL: ESTADO Do AMAZONAS: Alto rio Negro, ilha Gavião, abaixo da boca do rio Branco; 6-IX-1967; Byron 6782 (MG, INPA). Idem, idem; 13-X-1967; W. Rodrigues et L, Coelho 8350 (MG, INPA). - Idem, Padauiri, Tapera; 2-XI-1947; R. L. Fróes 22702 (IAN).

R. albuquerquei é bastante distinta das outras por seus ramos angulosos, folhas extremamente coriáceas e frutos brilhosos e doces (ao contrário das outras espécies, com frutos muito ácidos) .

Apresenta alguma afinidade com $R$. Iongifolia da qual se distingue principalmente por não apresentar o fenômeno da caulifloria. Os frutos de $R$. albuquerquei lembram um pouco os de $R$. brasiliensis.

Esta espécie é endêmica de uma região muito circunscrita do Médio Rio Negro (Amazônia Brasileira Ocidental).

Habita as margens arenosas, periodicamente alagadas, do rio.

3. Rheedia macrophylla (Martius) Planchon et Triana, Ann. Sci. Nat. 4e. sér. 14:309. 1890.

Garcinia macrophylla Martius Beibl, zur Flora $24(2): 35.1841$. 


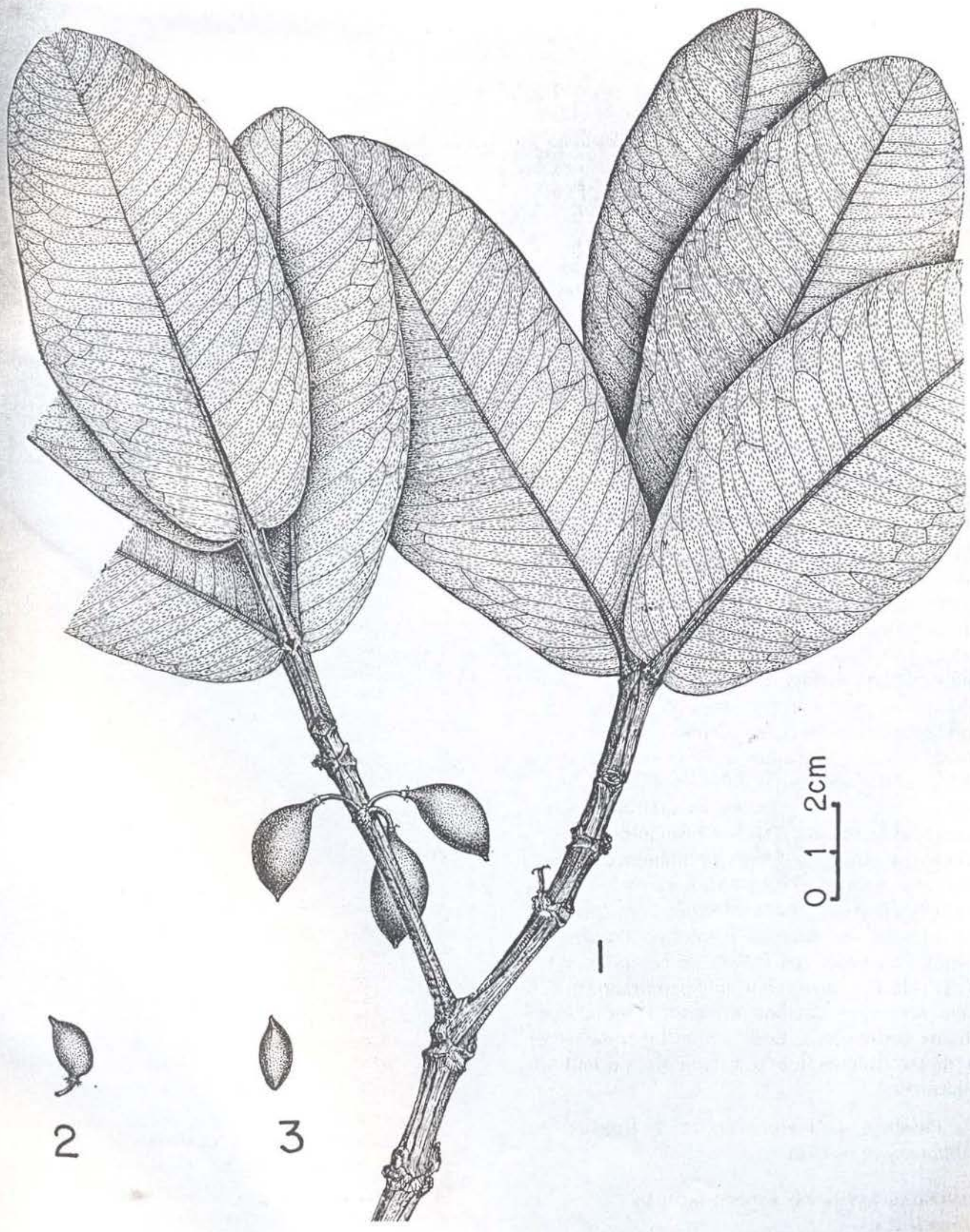

Est. 2 - R. albuquerquei (R. E. Schultes 24535): Fig. 1 - ramo frutifero; Fig. 2 - Fruto jovem; Fig. 3 semente. 
TYPUS: BRASIL: "Pará, in silvis", Martius 481 (holotypus M).

Árvores de $10-20 \mathrm{~m}$ de altura e $15-35 \mathrm{~cm}$ de diâmetro, com ramos em ângulo obtuso . Râmulos cilíndricos, tetrágonos em direção ao ápice, profundamente sulcados e nodosos; gemas foliares conspícuas. Folhas: pecíolo alongado, de $2-3 \mathrm{~cm}$ de comprimento e ca. de diâmetro, tetrágono, profundamente suicado no sentido longitudinal e rugoso transversalmente; lâmina de $16-40 \mathrm{~cm}$ de comprimento e $6,5-13 \mathrm{~cm}$ de largura, brilhosa em ambas as faces, coriácea, elíptico-oval, elíptico-oblonga ou elíptico-lanceolada (raro obovada), base aguda, arredondada ou levemente atenuada, ápice agudo, margem revoluta, ondulada; costa supra e infra-proeminente, sulcada, nervação secundária abundante, proeminente, mais ou menos paralela entre si, formando um ângulo de 60-75 $\mathrm{em}$ relação à costa e anastomosando-se sob a margem, reticulação densa e proeminente em ambas as faces, concentrada sob a margem. Botões florais globosos, pedicelos com $15-30 \mathrm{~cm}$ de comprimento. Flores masculinas: 15-25 em cada fascículo, inseridas sobre um pulvínulo de $4-8 \mathrm{~mm}$ de altura e $11-15 \mathrm{~mm}$ de diâmetro, tuberculado; sépalas esverdeadas, orbiculares, com ca. de $5 \mathrm{~mm}$ de diâmetro; pétalas brancas, obovadas com $8 \mathrm{~mm}$ de altura e 3-4m mde largura, semi-reflexas após a ântese: estames de 15-25. Flores hermafroditas: menos numerosas, de 5-10 por fascículo; disco de $2 \mathrm{~mm}$ de altura e $5 \mathrm{~mm}$ de diâmetro; ovário ovóideo, com $5 \mathrm{~mm}$ de altura e coroado por um estigma deltóide, caliptriforme, com $2 \mathrm{~mm}$ de altura e ca. de $6 \mathrm{~mm}$ de diâmetro. Fruto: liso, ovóide, amarelo, com $5-7 \mathrm{~cm}$ de comprimento e $4-5 \mathrm{~cm}$ de diâmetro, com ápice rostrado, rostro com até $1 \mathrm{~cm}$ de comprimento, coroado por restos do estigma, base aguda inserida sobre o disco concrescido e restos do perianto e androceu.

Floresce de maio a agosto e frutifica de outubro a fevereiro.

\section{MATERIAL ESTUDADO E DISTRIBUição GEOGRÁFICA:}

BRASIL: ESTAdO dO PARÁ: Belém, I-1963; J. M. Pires 8219 (R). - Idem, Feira do Ver-o Peso; 7-V-1968; P. Cavalcante (MG Carp. 1461).
- Idem, Mercado, IIl-1903; s/col. (MG carp. 624). - Idem, Horto Botanico; 1-VI-1908, J. Huber (MG 9351). - Idem, Jardim Botânico do Museu Goeldi, 8-II-1942; W. A. Archer 7544 (IAN). Idem, 10-XI-1948; A. Lima 48-61, (RB). Idem, Horto do Museu Goeldi. arv. 497; 10-X-1957; P. Cavalcante 311 (MG, IAN). - Idem; 28-VI-1975; M. E. van den Berg 95 (MG). - Idem, bairro da Pedreira; 22-X-1971; E. Oliveira 5939 (IAN). - Idem, igapó do Guamá; 25-VIII-1941; A. Ducke 783 (MG, IAN, R), - Iciem, "south forest of the I.A.N."; 25-XI-1942; W. A. Archer 7879 (IAN). - Idem, IPEAN, Reserva APEG, Q. 223-93; 13-X-1967, J. M. Pires \& N. T. Silva 11128 (IAN). - Breves, perto do igerapé Arapijó; 7-30-VII-1956; J. M. Pires et al. 4985 (IAN). Obidos, rio Branco de Obidos, rio Branquinho; 27-I-1918; $\mathbf{\Lambda}$. Ducke (MG 16957). - Regiăo do rio Jari, estrada entre Pilão e Repartimento; 20-I-1969; N. T. Silva i660 (IAN), - Rio Parú de Oeste, Missão Tiriyó, junto à aldeia. $2^{\circ} 20^{\prime} \mathrm{N}, 5^{\circ} 45^{\prime} \mathrm{W}, 13-\mathrm{II}-1970$; P. Cavalcante 2375 (MG).

EStado do amazonas: Manaus, estrada do Aleixo, Companhia Nacional de Plantações; IV-1965; J. Dubois (INPA 17041). Rio Solimōes, igarapé Belém, Lourenço Gaspar; 6-XII-1949; R. L. Fróes 23710 (IAN), - Margem direita do rio Solimōes, próximo a Manacapurú; 9-X-1972; O. Pires 243 (INPA, MG). - Rio Juruá. "near mouth of rio Embira, tributary of rio $\mathrm{Ta}$ rauacá", 7॰30'S, 70¹5’W: 12-VI-1933; B. A. Krukoff 4765 (SP). - Floresta de várzea próxima à serra do Arıcá; 22-II-1977; N. A. Rosa \& M. R. Cordeiro 1602 (MG)

ESTADO DO ACRE: Sena Madureira, $5 \mathrm{~km}$ a leste da cidade; 03-X-1968; G. T. Prance et Al. 7778 (MG). - Idem, "trail from W. bank of rio Iaco to rio Purus, $3 \mathrm{~km}$ above confluence"; 5-X-1968; G. T. Prance et al. 7874 (INPA). - Idem, "trail W. of rio Iaco from São Caetano, $18 \mathrm{~km}$ above Sena Madureira"; 8-X-1968; G. T. Prance et al. 7944 (INPA, MG).

ESTADO do MATo Grosso: Pedra Branca. rio Jauru; XII-1908; F. C. Hoehne 906 (R, SP). - Idem, XII-1908; F. C. Hoehne 923 (R).

TERRITÓRIO FEDERAL DO AMAPÁ: RIO Amapari, Campo 14; 8-X-1961; J. M. Pires et al. 51569 (MG, IAN). - Rio Oiapoque, igarapé Nataia; 6-II-1950; R. L. Fróes 25895 (IAN). - Oiapoque; VI-1904 A. Ducke (MG carp. 623). 


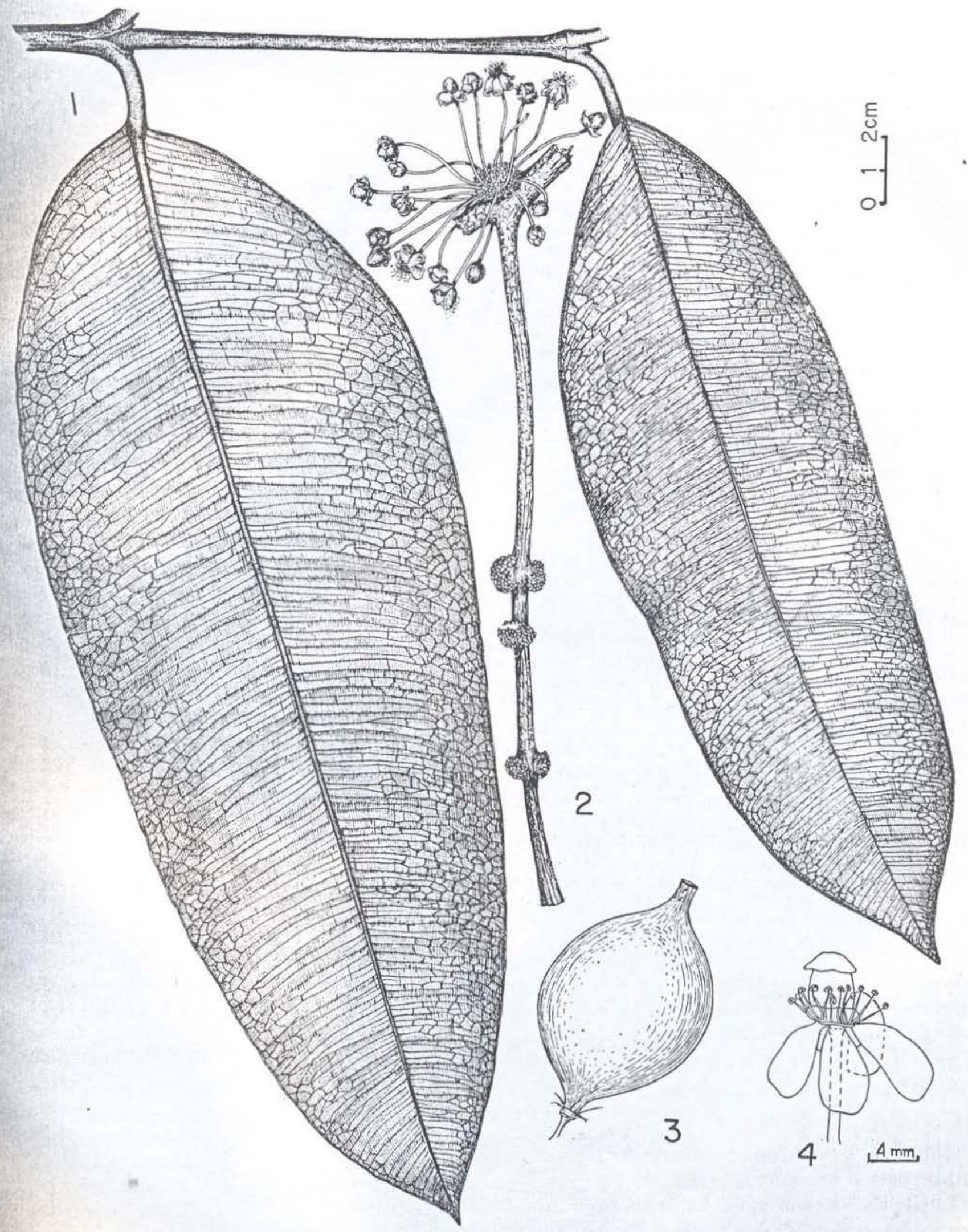

Est. 3 - R. macrophylla: Fig. 1 - ramo florifero (Ducke 783); Fig. 2 - ramo foliar (van den Berg 95); Fig. 3 - flor; Fig. 4 - fruto (van den Berg 95). 
TERRITÓRIO FEDERAL DE RORAIMA: BOa Vista; 24-IX-1931; Monteiro da Costa 480 (IAN).

- Base da serra Tepequem, Boca da Mata; 11-II-1967; G. T. Prance et al. 4314 (MG, INPA). - "Lower southwestern slopes of serra Tepequem, 600m alt."; 21-II-1967; G. T. Prance et al. 4592 (INPA. MG, R). - "Between Maitá - $3^{\circ} 20^{\prime} \mathrm{N}, 63^{\circ} 24^{\prime} \mathrm{W}$ and Paramiteri Indian Village, $3^{\circ} 25^{\prime} \mathrm{N}, 63^{\circ} 3^{\prime} \mathrm{W}$ ", 21-II-1971, G. T. Prance et al. 10653 INPA).

estado do Maranhño: Coroatá; "Road B22, Capanema to Maranhão - $\mathrm{km} 64$, vicinity of Peritoró; 5-XI-1965; G. T. Prance et T. D. Pennington 1997 (IAN).

ESTADO DE PERNAMBUCO: Recife, 22-III-1966, G. Mariz 330 (SP).

ESTAdo DA влнік: Ilhéus, Fazenda Pirataquisse; 1-III-1944; H. P. Vellozo 816 (R)

ESTADO DO RIO DE JANEIRO: Rio de Janeiro, Quinta de São Cristovão. s/d, Glaziou $15858(\mathrm{R})$.

\section{MATERIAL ADICIONAL :}

GUIANA FRANCESA: Rio Oiapoque, "about $0,5 \mathrm{~km}$ $\mathrm{N}$. of rio Ingarari, $2^{\circ} 18^{\prime} \mathrm{N}, 52^{\circ} 38^{\prime} \mathrm{W}, 16-\mathrm{IX}-1960$, H. S. Irwin et al, 48295 (MG, IAN), - Idem, 16-IX 1960, H. S. Irwin et al. 48296 (MG, IAN).

SURINAME: Watramiri, arbor n. 1670, 26-VI-1918 (BW 3907, IAN). - Brownsbergtop, 30-V-1924, (BW 6569, RB).

GUIANA: "Northwestern slopes of Kanukv Mountains, in drainage of Moku-moku Creek, Takutu tributary", 31-III - 16-IV-1938, A. C. Smith 3402 (IAN).

Rheedia macrophylla é uma espẻcie bem conhecida, característica por seus frutos ovóides com polpa ácida, e muito apreciada pelas suas grandes folhas verde escuro brilhosas. Ao lado de R. madruno é um dos poucos "bacuri-pari" cultivados, embora em pequena escala.

Está bem distribuida por toda a Amazônia. No Nordeste é encontrada na região litorânea do Estado de Pernambuco e Bahia. No Rio de Janeiro foi coletada apenas por Glaziou na Quinta da Boa Vista o que nos permite supor que se trata de uma planta introduzida, provavelmente trazida da Amazônia.
Habita as matas de terra firme, em geral sobre latossolos.

Nomes vulgares: bacuripari verdadeiro ( $\mathrm{Be}$ lém, Amapá), bacuri (Óbidos-PA, Manaus-AM); bacuri da várzea (Solimões-AM), pakoeli (Suriname), pacuriguazú (Paraguai) .

4. Rheedia gardneriana Miers ex Planchon et Triana, Ann. Sci. Nat. 4e. sér. 14: 321. 1860.

Lamprophyllum gardnerianum Miers. "in shed" (P).

Rheedia gardneriana Miers ex Planchon var. parvifolia Engler, in $\mathrm{Fl}$, Bras., 12 (1) : 463. 1888 .

Rheedia gardneriana Miers ex Planchon et Triana var. glaziovii Engler, 1.c., tab. 104, fig. 2 .

Rheedia spruceana Engler, 1.c. Typus: PERU: "Peruvia orientalis in silvis prope Tarapoto"; 1855. Spruce 4484 (holotypus $\mathrm{K}$, isotypus $\mathrm{B}$, phototypus IAN!).

Rheedia spruceana Engler var. cuneata Engler, 1.c.

Rheedia tenuifolia Engler, 1.s. Holotypus: BRASIL: Bahia, "ad. Ilhéus"; Blanchet $2337(\mathrm{~K})$.

Rheedia calyptrata Planchon et Triana. Ann. Sci. Nat. 4e. sér. $14: 311.1860$.

Tovomita calyptrata Schlecht in Linnaea 8.187. Typus: "Rio de Janeiro; Lhotzky 5" (holotypus P, phototypus IAN!).

TYPUS: BRASL: Ceará; Gardner 1922 (holotypus $\mathrm{P}$, isotypus $\mathrm{B}$, phototypus (AN!).

Árvores de $5-10 \mathrm{~m}$ de altura e $10-15 \mathrm{~cm}$ (raro $25 \mathrm{~cm}$ ) de diâmetro. Râmulos tetrágonos, sulcados nodosos. Folhas, pecíolo de $7-15 \mathrm{~mm}$ de comprimento, tetrágono, sulcado transversalmente e plicado; lâmina de $5,1-15 \mathrm{~cm}$ de comprimento e 2,9-5,2cm de largura, opaca em ambas as faces, cartácea ou subcoriácea (membranácea no ápice do ramo), elíptica ou elíptico-lanceolada, base aguda, atenuada e assimétrica, ápice agudo, acuminado ou longamente acuminado, margem abertamente revoluta, ondulada; costa supra e infra proeminente, sulcada, nervação secundária abundante, 


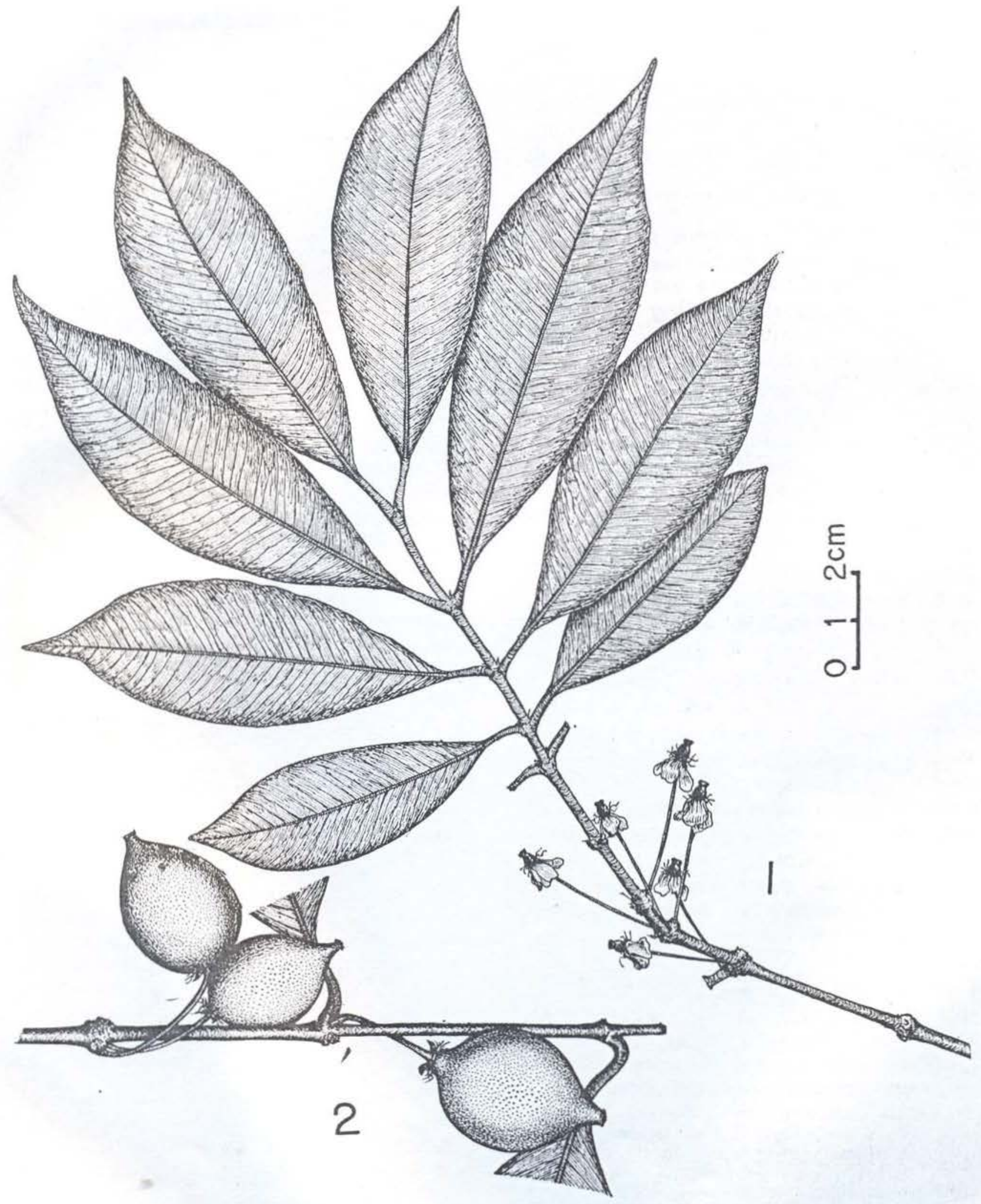

Est. 4 - R. gardneriana: Fig. 1 - ramo florífero (M. Kuhlmann 313); Fig. 2 - ramo frutífero (F. C. Hoene SP 27157). 
supra e infra proeminente, mais ou menos aberta, paralela entre sí, ascendente com algumas nervuras anastomosando-se sob a margem, reticulação conspícua. Botões florais globosos ou oblongos, pedicelos com $11-25 \mathrm{~mm}$ de comprimento. Flores masculinas: de 10-15, inseridas sobre um pequeno pulvínulo de 1-1,5mm de altura e 4-5mm de diâmetro; sépalas branco-esverdeadas, orbiculares, com ca. de $2 \mathrm{~mm}$ de diâmetro, pétalas alvas, ovadooblongas com $4-6 \mathrm{~mm}$ de altura e $2-3,5 \mathrm{~mm}$ de largura, fortemente reflexas após a ânteses, disco pulviniforme, com $0,8-1 \mathrm{~mm}$ de altura e 1,5mm de diâmetro; 12 -16 estames rigidamente eretos. Flores hermafroditas: $5-10$ por fascículo, inseridas sobre um pulvínulo semelhante ao das flores masculinas; disco de $0,8 \mathrm{~mm}$ de altura e $2 \mathrm{~mm}$ de diâmetro, longitudinalmente sulcado; ovário ovóideo com $2 \mathrm{~mm}$ de altura e ca. de $2 \mathrm{~mm}$ de diâmetro, coroado por um estigma pulviniforme com $1 \mathrm{~mm}$ de altura e $2 \mathrm{~mm}$ de diâmetro. Fruto: liso, amarelo esverdeado, ovóideo, com $2,8-4 \mathrm{~cm}$ de comprimento e $2-2,7 \mathrm{~cm}$ de diâmetro, rostro conspícuo com até $0,5 \mathrm{~cm}$ de comprimento, coroado pelo estig. ma remanescente, base arredondada ou aguda, inserida sobre o disco concrescido e restos do perianto e androceu.

Floresce de maio a agosto, frutificando de outubro a janeiro.

\section{MATERIAL ESTUDADO E DISTRIBUIÇÃO GEOGRÁFICA:}

BRASIL: ESTADO DO PARÁ: Ourém: 5-XIII-1903; R. S. Rodrigues (MG 4050). - Rio Guajará, região do Planalto de Santarém, Município de Prainha; 20-VII-1955; R. L. Fróes 31987 (IAN). - Rio Tapajós Estrada das Cachoeiras Inferiores, Piriquito; 11-IX-1916; A. Ducke (MG 16475). - Rio Tocantins, Remansão; 4-IX-1948; R. L. Fróes 23389 (IAN). - Rio Itacaiunas, Seco-Grande; 20-VI-1949; R. L. Fróes \& G. A. Black 24603 (IAN). - Idem; 20-VI-1949; R. L. Fróes \& G. A. Black (IAN 51073). Marabá, serra de Buritirama; 25-VI-1970; J. M. Pires \& R. P. Belém 122299 (IAN), - Idem; 27-VI-1970; J. M. Pires \& R. P. Belêm 12308 (IAN).

Estado do aMAZONAS: "Near mouth of rio Embira, Basin of rio Juruá, lat. $7 \circ 30 \mathrm{~S}$, long. $70^{\circ} 15^{\prime}$ W, B. A. Krukoff 5102 (SP). Rio Javari, Tambaqui; 18-X-1976; G; T.
Prance et al. 23908 (MG). - Ipixuna, Purus, Bom Lugar; III-1904; A. Goeldi (MG 4232). - Boca do Acre; 25-X-1975; O. P Monteiro (INPA 53470).

TERRITÓRIO DE RORAIMA: Surucucu, "betwen Maitá Mountains and Maitá indian village. 3¹5'N, 63॰28' - 24'W"; 13-II-1971; G. T. Prance et al. 10494 (MG).

TERRIT́́RIO DE RONDONIA: Bacia do rio Madeira, "N. bank of R. Madeira betwen cachoeira Tres S and Fortaleza, $4-16 \mathrm{~km}$ above mouth"; 18-VII-1968; G. T. Prance et al. 6176 (MG).

estado do CeArá: Baturité; s/d; Fr. Alemão et M. Cysneiros 180 ( $R$ ). - Uruburetama; s/d; Fr. Alemão et M. Cysneiros (R 79141). ESTADO DE PERnAmbuco: Recife, Dois Irmãos, corgo do Visgueiro Grande, 23-X-1975, G. Mariz 650 (UFPe.) - Idem, mata de Dois Irmãos; s/d, Dárdano de A. Lima 1365 (IAN). - Vicência, Mata do Engenho, Jundiá; 12-XI-1960; S. Tavares 547 (I'LEP). EStado DA BaHia: Água Preta; XII-1937, G. Bondar 2271 (SP).

ESTADO DE MINAS gERAIS: S. Domingo, "slope above stream, alt. 720m"; 19-XI-1930; X. Mexia 5323 (RB). - Rio Branco, 750m alt.; 13-XI-1930; Y. Mexia 5297 (R). - Caldas; S/d; Regnell 1528 (R), - S/Inf. (R 79148). ESTADO DO RIO DE JANEIRO: Inspetoria Florestal (E. de F. Central do Brasil), espécie n. 50; s/d; (R 27640). - Tijuca; IX-1882; (RB 88402). - Idem; 7-IX-1974; A. Glaziou 7527 (R.). Idem; 27-IX-1882; A. Glaziou 13579 (R). - Dois Irmãos; 19-VIII-1924; Mata do Pai Ricardo, perto do Horto Florestal (Rua D. Castorina); 2-XI-1926; Pessoal do Horto ( $R$ 136102). - Parque Nacional da serra dos Orgãos, a $900 \mathrm{~m}$ de alt.; 19-XI-1952; J. Vidal II 5310 (R). - Idem; 1-XII-1883; Manduca Palma (R 79055). Terezópolis, Fazenda Boa Fé, mata do Jardim; 16-II-1943; H. P. Veloso 291 (R). Nova Friburgo, Alto Macaé; 18-XI-1891; A. Glaziou 18155 (R). - Avelar, Pau Grande; 1931; G. Machado Nunes 50 (R).

estado de Sĩo Paulo: S. Paulo, nativa do Parque do Estado (Jardim Botânico); 11-XI-1931, F. C. Hoehne 1882 (SP). Idem. 6-XI-1945; M. Kuhlmann 3132 (SP). - Idem, Cemitério da Xiririca; 16-X-1894; Loefgren et Edwall (SP 28262). - Idem; 25-IX-1929; F. C. Hoehne (SP 24298). - S. Vicente, ilha Porchat; 10-X-1955; F. C. Hoehne (SP 27156). - Idem; 10-X-1955, W. Hoehne (SPF 5594). - Alto da Serra, mata da Estaçāo Biológica; 28-II-1923; 
F. C. Hoehne (SP 8358). - Iguape, morro das Pediras; X-1919; A. C. Brade 7906 (SP). ESTADO DO PARANÁ: Paranaguá, Praia do Leste, 2-X-1929, F. C. Hoehne (SP 24334).

Estado de santa catarina: Brusque, mata do Hoífmann, 30-XII-1949; H. P. Veloso 9 (RB). - Sombrio, alt. 10m; 3-IX-1945; R. Reitz 1917 (R).

ESTADO DO RIO GRANDE DO SUL: S. Leopoldo, Gravatas; s/d; J. Dutra (R 79263). - Santa Anna do Rio dos Sinos; s/d; s/col. (R 78967).

PERU: DEPARTAMENTO DE LORETO: "Puérto Arturo, lower rio Huallaga, below Yurimaguas, alt. above 135m"; 24/5-VIII-1929; E. P. Killip \& A. C. Smith 21801 (RB).

Quando Engler (1888) descreveu as suas novas espécies $R$. spruceana e $R$. tenuifolia e, suas variedades, baseou-se em material escasso e sem frutos, que na sistemática do gênero Rheedia são fundamentais. As características foliares apontadas por Engler, para distinguir $R$. gardneriana, e suas variedades parvifolia e glaziovii, R. spruceana e sua variedade cuneata e ainda $R$. tenuifolia, não podem ser consideradas uma vez que, foram encontradas num mesmo ramo, de uma só exsicata, em repetidas amostras. Como exemplo mais característico deste fato podem ser indicadas as coleções de Fróes \& Black 24603, Fróes \& Black (IAN 51073), Ducke (MG 16475), Pires \& Belém 12308 e Bondar 2271. Os frutos de todas essas espécies e variedades são idênticos. Também não há diferenças significantes entre as flores das espécies e variedades criadas por Engler $\mathrm{e}$ as de $R$. gardneriana. Trata-se de uma única espécie, isto é, R. gardneriana, que foi a primeira a ser classificada e descrita.

Ainda com referência a $R$. spruceana, devese acrescentar que o exemplar Spruce 1744, citado por Engler, em primeiro lugar, na lista de material examinado, é de uma legítima $R$. brasiliensis. Portanto, a coleção Spruce 4484 - (também citada por Engler) é a que deve ser considerada um "holotypus" para este nome.

Tanto R. calyptrata PI. et Tr., como seu basiônimo Tovomita calyptrata Schlecht, devem ser considerados sinônimos de $R$. gardneriana por não apresentarem caracteres distintivos que justifiquem sua manutenção como "taxon" válidio.

Nomes vulgares: bacupari (São Paulo, Santa Catarina e Rio Grande do Sul), bacoparé (Minas Gerais).

5. Rheedia brasiliensis: (Martius) Planchon et Triana, Ann. Sci. Nat. 4a. sér. 14: 310. 1860.

Garcinia brasiliensis Martius Beibl. Zur Flora 24 (2): 33. 1841.

Garcinia brasiliensis Martius forma major Martius, 1.c.: 34 .

Rheedia floribunda "sensu" Engler in Fl. Bras. 12 (1) : 464. 1888. "pro parte".

Garcinia floribunda "sensu" Miquel Stirp. Surinam. Selec.: 90, 1850. "pro parte".

TYPUS : BRASIL: Luschnath., M. Lucae, 1836 (holotypus $M$ ).

Árvores de $5-10 \mathrm{~m}$, podendo alcançar $15 \mathrm{~m}$ de altura e $10-15 \mathrm{~cm}$ de diâmetro, com ramos em ângulo obtuso. Râmulos cilíndricos, sulcados. Folhas: pecíolo alongado, de $1-1,8 \mathrm{~cm}$ de comprimento e ca. de $3 \mathrm{~mm}$ de diâmetro, subcilíndrico, canaliculado, com uma fóvea característica na base, revoluto em direção à nervura central rugoso transversalmente, lâmina de $7-23,5 \mathrm{~cm}$ de comprimento e $5-9,5 \mathrm{~cm}$ de largura opaca em ambas as faces, coriácea, oval ou elíptico-oval, em geral assimétrica, base arredondada ou atenuada, ápice agudo ou levemente acuminado, margem estreitamente revoluta, ondulada; costa supra proeminente, infra mais conspícua, sulcada, nervação secundária abundante, disposta obtusamente em relação à costa, arqueando-se e anastomosando-se sob a margem, onde apresenta reticulação irregular e proeminente em ambas as faces. Botões florais globosos, pedicelos com $15-21 \mathrm{~mm}$ de comprimento. Flores masculinas: pouco numerosas (10-15) em fascículos com aspecto verticilado, inseridas sobre um pulvínulo pouco conspícuo; sépalas branco-esverdeadas, suborbiculadas, côncavas, muito delicadas, membranáceas, com $2 \mathrm{~mm}$ de altura e 1,5mm de largura; pétalas alvas, obovadas, estriadas, com $3,5 \mathrm{~mm}$ de altura e 2,5mm de largura, reflexas após a antese; estames de 20-30. Flores hermafrodi- 


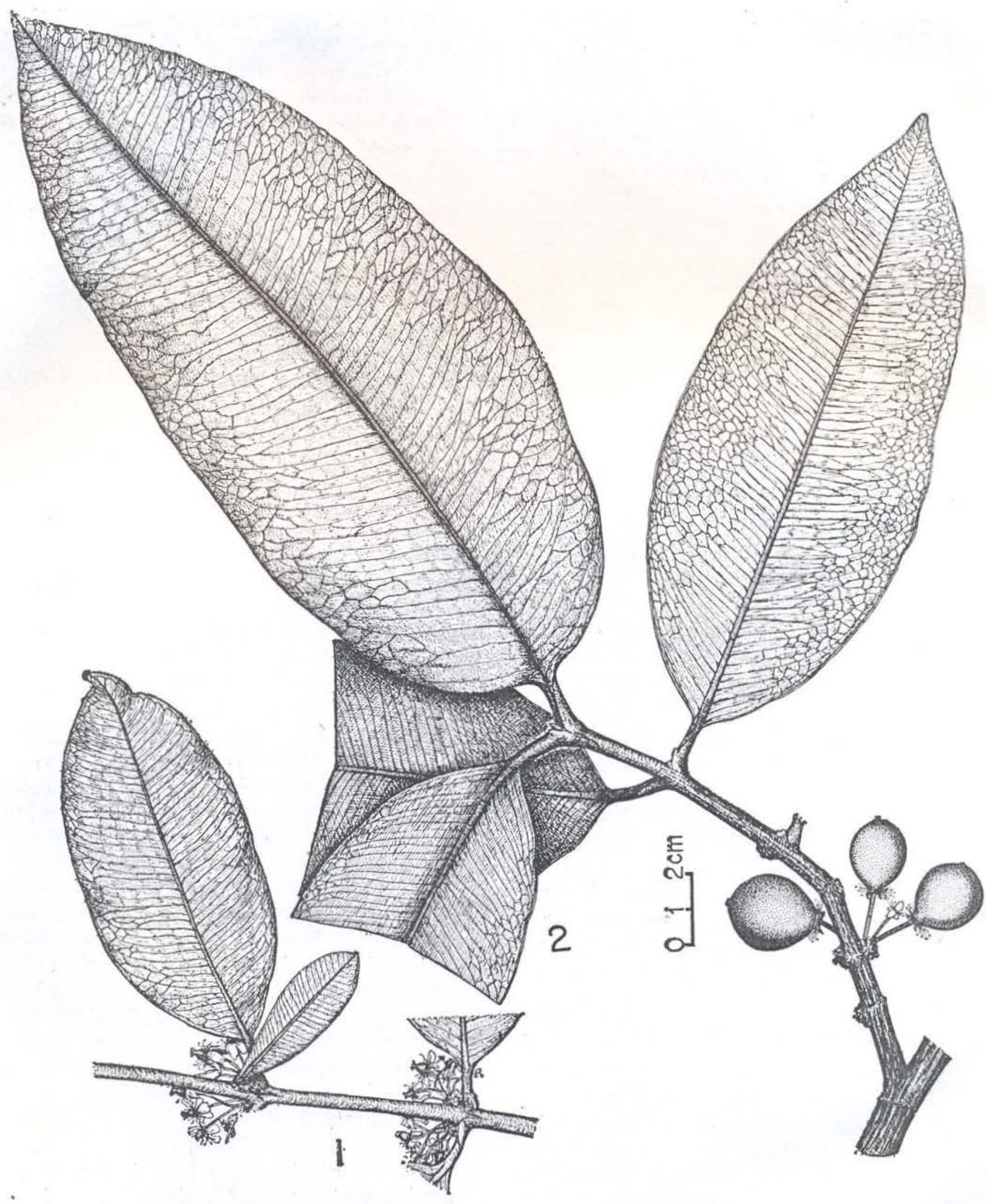

Est. 5 - R. brasiliensis: Fig. 1 - ramo florifero (Glaziou 18154); Fig. \& - ramo frutifero (M. Silva 749). 
tas: $3-5$, disco de ca. de $1 \mathrm{~mm}$ de altura e ca. de $2 \mathrm{~mm}$ de diâmetro; ovário ovóideo de $3 \mathrm{~mm}$ de altura e 2,5mm de diâmetro, coroado por um estigma pulviniforme $\mathrm{com} 1 \mathrm{~mm}$ de altura e $2,5 \mathrm{~mm}$ de diâmetro. Fruto liso, amarelo e alaranjado, elipsóide, com $2,0-2,5 \mathrm{~cm}$ de comprimento e $1,5-2,2 \mathrm{~cm}$, com ápice arredondado ou pouco pronunciado, coroado por estigma remanescente, base mais estreita, assentado sobre restos do disco, estames e pétalas.

Floresce de março a agosto e frutifica de setembro a janeiro.

\section{MATERIAL ESTUDADO E DISTRIBUIÇÃO GEOGRÁFICA:}

BRASIL: estado do pará: Belém, Museu Goeldi, novo cercado dos jabotis; 23-IV-1971; P. Cavalcante 2770 (MG). - Óbidos; 1905; Paul LeCointe (MG 7046). - Idem, margem do lago Curumum; 3-I-1914; A. Ducke (MG 15296). - Porto de Moz, Praia Grande; 26-II-1916; A. Ducke (MG 16672).

ESTADO do AMAZONAS: Manaus, rua da cidade; 19-VIII-1973; P. L. Lisboa 15 (INPA). - Idem, km 9 de BR-17 (Manaus-Itacoatiara); 27-V-1956; J. Chagas (MG 48035). - Idem; 26-III-1956; Luiz 3674 (MG, INPA) - Idem, Cachoeira Baixa do Tarumá, pró. ximo so rio; 17-XI-1966; G. T. Prance et al. 3190 (MG, INPA). - Idem, igarapé Ponta Negra, afluente do rio Negro; 22-IV-1953; R. L. Fróes 29592 (IAN). - Rio Negro, S. Gabriel da Cachoeira; s/d; Spruce 2377 (MG, Ex-BM; citado na Flora Bras.). Idem "in vicinibus Barra, Prov. Rio Negro", XII-1850 - III-1851, Spruce 1744 (MG, idem, idem). - São Paulo de Olivença, 2-IV-1944, A. Ducke 1573 (MG) Idem, igarapé Belém; 14-XII-1949; R. L. Fróes 23709 (IAN). - Rio Solimōes, Mana. capuru, beira do lago do Jacaré; 1-V-1967; M. Sitva 745 (MG). - Idem, Tonantins, igapó ao lado do Solimões; 21-II-1944; $\mathbf{A}$. Ducke 1572 (MG, R). - Tefé; 18-VIII-1947; G. A. Black 47-1214 (IAN). - Idem, 8-VI-1850, R. L. Fróes 26142 (IAN). - Rio Javari, Munic. Benjamim Constant, ilha Aramaçá, defronte Tabatinga; 23-VII-1973; G. T. Prance et al. 16760 (MG). - Idem; 24-VII-1973; G. T. Prance 16801 (MG). Santo Antonio do Içá; 30-VIII-1906; A. Ducke (MG 7639).

ESTADO DO ACRE: Abunã, Seringal Orion; 23-X-1923; J. G. Kulmann 706 (RB). - Seringal Boa Água; VII-1972; J. M. Pires et al. 13740 (IAN). - Rio Macacau, afl, do rio Iaco; 19-I-1975; B. S. Pena (IAN 146.512).

ESTADO DE MATO GRosso: "Barra do Garças - Xavantina Road, $20 \mathrm{~km}$ from Xavantina"; 12-VI-1966; D. R. Hunt \& J. F. Ramos 5965 (SP). - Rio Suia Missu, 12॰49'S, 51046'W; 20-XI-1968; R. M. Harley \& R. Souza 11146 (IAN, RB). - Cáceres, VIII-1911, F. C. Hoehne 4351-4, 4356-7 (R, SP).

estado do Maranhão: Pedreiras, 7-VII-1909; F. Q. Lima (MG 2315). - Imperatriz, capoeira à beira do rio Tocantins, 9-VIII-1949, J. M. Pires \& G. A. Black 1770a (IAN). - Pinheiro, Morro do Finca, arredores do campoz de Pinheiro; 06-VII-1978; N. A. Rosa et O. Cardoso 2539 (MG).

ESTADO DE PERNAMBuCo: Recife, Dois Irmãos, chã de Mamajuda, 4-I-1965; G. Mariz 193 (UFPe).

ESTADO DO RIO DE JANEIRO: Rio de Janeiro, São Cristovão, Quinta da Boa Vista; 6-XII-1866; Glaziou 18154 (R). - Leblon; VIII-1926; D. Constantino (RB 21323). - Restinga de Copacabana; 2-V-1889; Schwacke 6488 (RB). - Barra da Tijuca; 11-X-1926; J. G. Kuhlmann 284 (RB). - Lagoa de Piratininga; 8-XI-1922; J. G. Kuhlmann (RB 21324) . - Restinga de Jacarepagua; 10-IV-1958; E. Pereira et al. 4173 (RB). - Idem, Recreio dos Bandeirantes; 16-IV-1958; E. Pereira et al. 3571 (RB). - Teresópolis, Parque Nacional da Serra dos Órgãos; 19-XI-1952; J. Vidal 5310 (R). Idem; 13-XII-1952; J. Vidal $5612(\mathrm{R})$.

ESTADO DE SÃo PAULO: Nova Europa, Fazenda Itaquerê; 28-IV-1955, M. Kuhlmann 3676 (SP).

estado do PARANá: Paranaguá, Matinhos; 23-X-1948; G. Hatschbach 1049 (RB).

MATERIAL ADICIONAL :

GUIANA FRANCESA: Defronte da Colônia Agrícola do Oiapoque, cerca de $4 \mathrm{~km}$ ao Norte da foz do rio Cricu; 12-VIII-1960; J. M. Pires 47411 (MG, IAN).

PARAGUAI: E. Hassler 7038 (RB).

Rheedia brasiliensis é a única espécie que apresenta flores perfumadas. A sua morfologia foliar é muito susceptível às condiçōes ecológicas, daí os problemas taxonômicos sur- 
gidos entre os botânicos mais antigos. Na res. tinga, as suas folhas são bem mais coriáceas, com ápice agudo, nervação secundária semiimersa enquanto que na mata Amazônica apresenta folhas mais delgadas com ápice variando de pouco a extremamente acuminado, formando uma espécie de goteira. O seu fruto é comestivel e bastante apreciado, principal. mente pelas crianças. Encontra-se em estado silvestre na Amazônia, tendo sido também encontrada em roças abandonadas por indigenas.

Ocorre ao longo da calha do rio Amazonas e do rio Negro, no litoral Nordestino e do Sudeste, sendo que, para o litoral paranaense tratâ-se de uma ocorrência nova.

Habita as matas da terra firme, em gerai sobre latossolos ou nas matas de restinga (no sul do país).

6. Rheedia acuminata (Ruiz et Pavon) Planchon et Triana, Ann. Sci. Nat. 4e. sér. 14: 314. 1860 .

Verticillaria acuminata Ruiz et Pavon, Syst. F1. Peruv.: 140. 1798.

Rheedia floribunda (Miquel) Planchon et Triana, 1.c.: 319.

Garcinia floribunda Miquel Stirp. Surinam. Select.: 89. 1850. Typus: "In Surinami regionibus interioribus"; Kapler et Hostmann 593a (holotypus $\mathrm{P}$, isotypus $\mathrm{U}$, phototypus IAN!).

Rheedia acuminata (Ruiz et Pavon) Planchon et Triana, var. floribunda (Miquel) Vesque in DC. Mon. Phan. 8:510. 1893.

Rheedia rostrata (Miers) Vesque, Epharm. 2:24, tab. 72. 1889.

Verticillaria rostrata Miers "in shed". Holotypus: BRASIL: "Prov. Alto Amazonas, prope Panuré et rio Uaupés; R. Spruce 2609 (P, phototypus IAN!).

Rheedia kappleri Eyma, Meded. Bot. Mus. \& Herb. Rikjs. 4:26, tab. 5 (a-e). 1932. (renomeação ilegitima de R. floribunda),

TYPUS: PERU: "In Huancahuari"; Ruiz et Pavon (holotypus B, phototypus IAN!).

Árvores de $7-20 \mathrm{~m}$ (podendo alcançar $30 \mathrm{~m}$ ) de altura e $16-30 \mathrm{~cm}$ de diâmetro, com ramos semi-ascendentes. Râmulos cilíndricos, achatados e tetrágonos em direção ao ápice.
Folhas: pecíolo de $11-15 \mathrm{~mm}$ de comprimento e ca. de $3 \mathrm{~mm}$ de diâmetro, cilindrico, supra canaliculado; lâmina de $7-16 \mathrm{~cm}$ de comprimento e $4-6,5 \mathrm{~cm}$ de largura, opaca em ambas as faces, subcoriácea, elíptica ou elíptico-oval, raro oboval, base arredondada, ápice agudo ou acuminado, margem revoluta e pouco ondulada; costa supra patente e infra proeminente. longitudinalmente sulcada, nervação secundária numerosa, nervuras mais ou menos regularmente distanciadas entre si, anastomosando-se sob a margem sob a qual há reticulação proeminente; presença de finas linhas longitudinais em toda extensão da lâmina. Botões florais ovóide-piramidais, pedicelos de $1-2 \mathrm{~cm}$. Flores masculinas: 25-40 em cada inflorescência, inseridas sobre um pulvinulo tuberculado conspícuo $(1,5-3 \mathrm{~mm}$ de altura e $3-5 \mathrm{~mm}$ de diâmetro), sépalas orbiculares com ca. de $2,5 \mathrm{~mm}$ de diâmetro, pétalas oblongas ou obovadas, com $8 \mathrm{~mm}$ de altura e $4,5 \mathrm{~mm}$ de largura, totaimente reflexas após a ântese; estames 25-30, anteras recurvadas, disco tuberculado. Flores hermafroditas: 3-10 em cada fascículo, estames de 10-15, disco irregularmente lobado, com $1 \mathrm{~mm}$ altura e $3 \mathrm{~mm}$ de diâmetro; ovário ovóideo, tuberculado, com $3,5 \mathrm{~mm}$ de altura e $3 \mathrm{~mm}$ de diâmetro; estigma com $3 \mathrm{~mm}$ de diâmetro, caliptriforme com uma típica incisão de $1 \mathrm{~mm}$ de comprimento no sentido radial. Fruto muricado tendendo a equinado, forma variável, de alongado $(4,5 \mathrm{~cm}$ de comprimento e 3,5 a $4 \mathrm{~cm}$ de diâmetro), com rostro mais pronunciado, a ovóide $(4,5 \mathrm{~cm}$ de comprimento e 3,5 a $4 \mathrm{~cm}$ de diâmetro) com rostro pouco evidente ou quase ausente, com 3 sementes; na base, presença do disco desenvolvido juntamente com o fruto.

Floresce de maio a agosto, frutificando de outubro a março.

\section{MATERIAL ESTUDADO E DISTRIBUIÇÃO GEOGRÁFICA:}

BRASIL: ESTAdo do PARÁ: Belém, Horto do Museu Goeldi; 25-III-1971; P. Cavalcante 2769 (MG). - Idem, idem; 28-VI-1975; M. E. van den Berg 96 (MG). - Idem, Bosque Municipal Rodrigues Alves; 15-III-1901; I. Guedes (MG 2171). - Idem, idem; 4-VIII-1947; N. T. da Silva 23 (IAN, R). - Idem, vizinhança da cidade; 9-X-1961; J. M. Pires 51858 (RB), - Idem, IPEAN; 


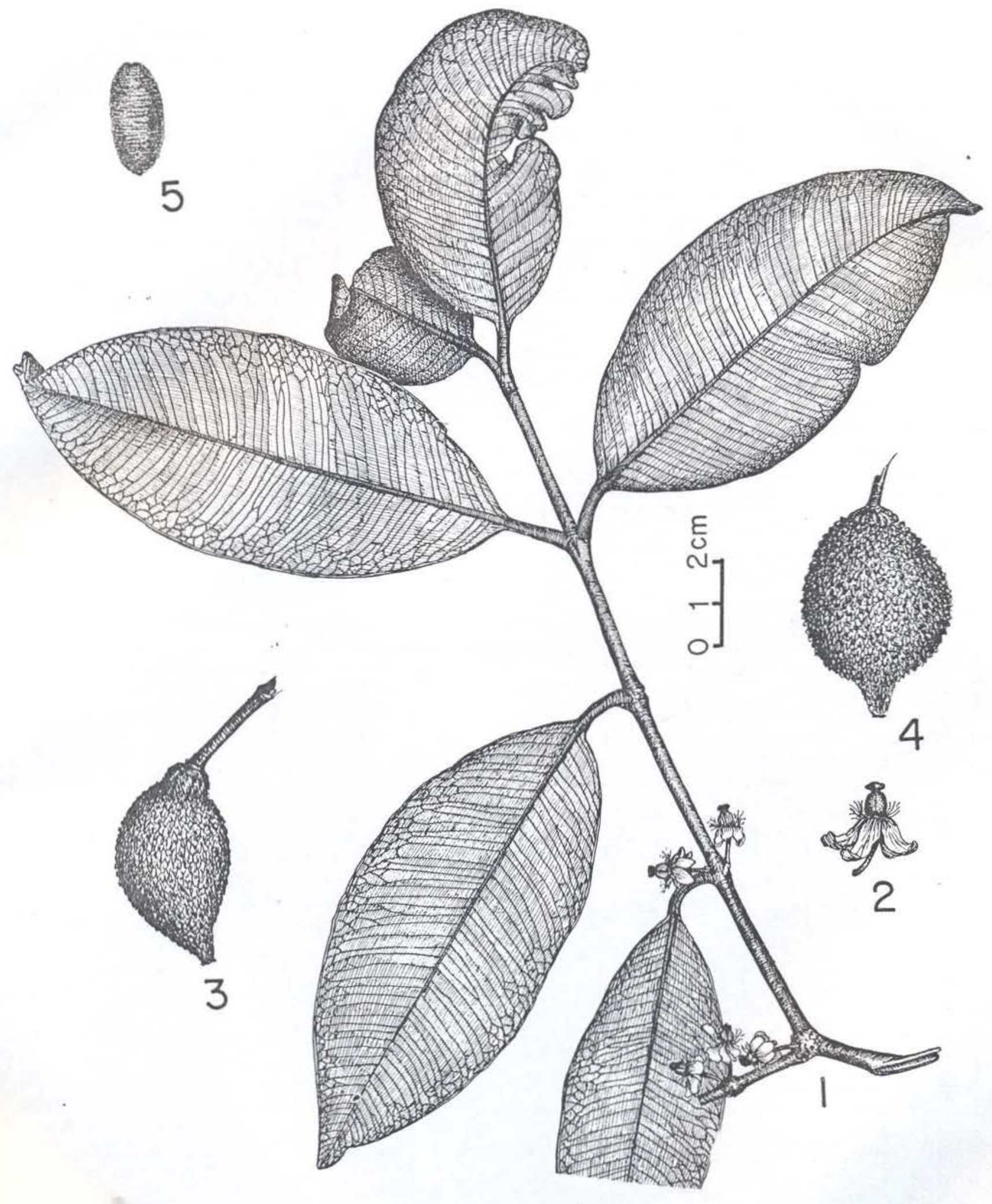

Est. 6 - R. acuminata: Fig. 1 - ramo florífero; Fig. 2 - flor (BW 1618); Figs. 3 e $4-$ frutos; Fig. 5 - se. mente (A. Goeldi, Carp. MG 623). 
13-IX-1967; J. M. Pires et al. 10966 (IAN). - Idem, Idem, Reserva do Mocambo, L 20-24, arv. 64; 15-VI-1967; J. M. Pires \& N. T. Silva 10541 (IAN). - Idem, idem. igapó do Catu, trasecto $10 \times 950 \mathrm{~L} 16 ; \mathrm{Q} 1$ SN; 25-X-1966; J. M. Pires \& N. T. Silva 10277 (IAN), - Idem, Reserva Aurá (IPEAN), Transecto Q. 105-68; 14-VIII-1967; J. M. Pires e N. T. Silva 10685 (IAN). E. F. Bragança, Santa Izabel, Moema; 2-IX-1908; Pessoal do Museu (MG 9612, INPA). - "Road BR-22, Capanema to Maranhão, vicinity of Cachoeira, $\mathrm{km} \mathrm{96";}$ 27-X-1965; G. T. Prance 1713 (IAN) . - Breves, rio Mapuá, perto do Marco de 1902, lago Bernarđinho. 23-VII-1950; G. A. Black et al, 9852 (IAN). - Tucurui, Vitória; 17-IV-1929; J. G. Kuhlmann 2018 (RB). Santarem, R. Maicá; 4-II-1968; M. Silva 1358 (MG). - Rio Tapajós, aeroporto de Jacareacanga; 30-I-1952; J. M. Pires 4047 (IAN). - Alto Tapajós, Vila Nova, perto da cachoeira do Chacorão; 27-XII-1951; J. M. Pires 3690 (IAN), - Idem, idem, 24-I-1952; J. M. Pires 4025 (IAN). Almeirim, serra de Aramanduba; 27-VIII-1918; A. Ducke (MG 17268). - Regiāo do rio Jari, entre serra de Almeirim e serra Azul; 27-VIII-1968; N. T. Silva 895 (IAN). Idem, idem, margem do igarapé Manguba; 14-XI-1967; E. Oliveira 3529 (IAN). Idem, idem. estrada do Munguba $\mathrm{km} \mathrm{14}$; 16-VI-1969; N. T. Silva 2201 (IAN). - Idem, idem, idem, $\mathrm{km} \mathrm{10;22 \cdot X-1970;} \mathrm{N.} \mathrm{T.} \mathrm{Silva}$ 3386 (IAN).

estado do amazonas: Manaus; 7-IV-1971; P. Cavalcante 2910 (MG). - Idem, estrada do Aleixo; 27-V-1941; A. Ducke 714 (MG. R). - Idem, km 9 da BR-17; 02-VI-1955; J. Chagas (MG 21196, INPA). - Idem, igarapé do Buião; 24-V-1956; Dionisio (MG 48036, INPA). - Idem, Reserva Florestal Ducke; 12-VIII-1966; W. Rodrigues \& Os. marino 8217 (MG, INPA). - Idem, idem, XI-1972; W. Rodrigues 9141 (INPA). Itacoatiara, $\mathrm{km} 21$ da rodovia Itacoatiara-Manaus, arredores do seringal; 11-XI-1963; E. Oliveira 2976 (IAN) . - Ro dovia Manaus-Porto Velho, km 160 igapó Tupanã; 23-III-1974; D. G. Campbell et al. P 20866 (MG). - Rio Negro, igarapé Ja. raqui; 22-IV-1967; M. Silva 947 (MG). Idem, próximo ao rio Arara; 27-IV-1973; A. Loureiro et al. (MG 48072, INPA). Borba, rio Canumä. lugar Niterói; 2-IV-1960; W. Rodrigues 1611 (INPA). Idem, Paraná do Autaz-Mirim, lago da Co. bra; 25-VIII-1973; C. C. Berg et al. P 19734 (MG). - Rio Solimões, S, Paulo de Oli- vença, igarapé Belém; 24-XII-1948; R. L. Fróes 23773 (IAN). - Idem, próximo à Fonte Boa; 22-VIII 1973; G. T. Prance et al. 17453 (MG). - Idem, Tonantins; 15-II-1944; A. Ducke 1570 (MG, R). - Idem, idem, "em antigas cuituras indigenas"; 15-II-1944; A. Ducke 1571 (MG, R) . - "Basin of 110 Demeni, vicinity of Totatobi”; 27-II-1959; G. T. Prance et al. 10293 (MG, INPA) . Rio Purus; 1903; A. Goeldi (Carp. IMG 623). - Tefé, "sítio abandonado na mata"; 29-VI-1906; A. Ducke (MG 7396, RB), - Rio Içá; 1906; A. Ducke (Carp. MG 615).

ESTADO DO ACRE: Rio Moa, Estação Agrícola a $15 \mathrm{~km}$ NW de Cruzeiro do Sul; 25-X-1966; G. T. Prance et al, 2793 (MG, INPA). Cruzeiro do Sul (río Juruá) $2,5 \mathrm{~km}$ ao $\mathrm{S}$ da cidade; 3-XI-1966; G. T. Prance et al. 2981 (MG, INPA). - Idem, Projeto RADAM, sub-base Cruzeiro do Sul ponto 5 SB 18 ZB; 19-II-1976; L. R. Marinho 243 (IAN). - Proximidades da boca do rio Embora, tributário do rio Tarauacá; 19-VI-1933; B. A. Krukoff 4919 (RB). Proximidades da foz do rio Macauhan, tributário do rio Yaco, lat, $9^{\circ} 20$ 'S, long. 69॰W; VIII-1933; B. A. Krukoff 5473 (RB).

ESTADO DE MATO GRosso: "Sandy east bank of rio Aripuanã, north of Humbolt Campus, $59^{\circ} 21^{\prime} \mathrm{N}, 10^{\circ} 12^{\prime} \mathrm{W}^{\prime}$; 9-X-1974; G. T. Prance et al. 18311 (MG). - Humbolt, à margem da cachoeira Andorinha, 26-VII-1974, N. A. Rosa et al, 159 (IAN). - Aripuanã, Dardanelos, "mata que cerca o salto das Andorinhas"; 29-IX-1975: P. Lisboa et al. 476 (INPA).

TERRITÓRIO FEDERAL DO AMAPÁ: Rio Oiapoque, "about $2 \mathrm{~km} \mathrm{~N}$ of mouth of rio Maturá, $2^{\circ} 35^{\prime} \mathrm{N}, 52^{\circ} 32^{\prime} \mathrm{W}^{\prime \prime} ; 22-\mathrm{IX}-1960$; H. S. Irwin et al. 48429 ( $M G$, IAN, RB)

ESTADO DE Golís: Rio Piranha, afluente do rio Araguaia, regiâo de Araguatins, 27-IV-1961; E. Oliveira 1602 (IAN).

\section{MATERIAL ADICIONAL :}

GUIANA FRANCESA: Margem do rio Maroni; 1862; Melinon s/n, Herb. J. de Saldanha 358, ex. Herb. P (R). - Rio Oiapoque, "middle slopes of Mt. Tipac., alt. $100-200 \mathrm{~m}, 3{ }^{\circ} 36^{\prime} \mathrm{N}$, 51॰19`W"; 14-X-1960, H. S. Irwin 48719 (MG, IAN).

SURINAME: "Via Secta Moengo Tapoe ad Grote Zwiebelzwamp"; 28-IX-1948, J. Lanjow \& J. C. Lindemann 517 (IAN), - Zanderij I; V-1944; Woodherbarium Surinam 204 (IAN). - Idem, arbor n.॰ 103, 10.XI-1915, s/leg. (BW 
1261, RB). - Sectie O, arbor 270a., s/d, s/leg. (IAN 38498a.). - Idem, arbor n. 589; II-1916, s/leg. (BW 1618, IAN, RB). Idem; 4-V-1916, s/leg. (BW 1818, IAN). Watramiri, arbor n. ${ }^{\circ}$ 1604; 6-VI-1916; s/leg. (BW 1959, IAN).

GUIANA: "Kaieteus Plateau, along Potaro River, above Kaiatuk"; 10-X-1944, B. Maguire 23373 (RB)

R. acuminata é uma das espécies mais con trovertidas embora seja facilmente distinta por seus frutos rostrados, que podem se apresentar de verrucosos a semi-equinados. Os frutos jovens lembram os de $R$. benthamiana, porém ao desenvolver-se mostram mais semeIhança com os frutos de $R$. madruno.

$R$. acuminata é freqüentemente confundida com $R$. brasiliensis, $R$. benthamiana e $R$. madruno, quando só apresenta material florífero, por causa das semelhanças que reaimente apresentam suas flores e folhagens.
É também entre as espécies revistas a que apresenta maior número de sinônimos.

Entre estes, R. floribunda é binômio longamente questionado pelos autores. Quando Miquel (1850) descreveu Garcinia floribunda (basiônimo de Rheedia floribunda), indicou claramente Kappler 593a (U) como o material em que se havia baseado. Porém, indicou como sinônimo dessa espécie Garcinia brasiliensis Martius forma major o que é incorreto, porque essa forma, atribuida a Martius, é uma legítima $R$. brasiliensis. Além disso, Martius (1841) não fez referência específica a uma forma major em seu trabalho. Provavelmente, Miquel se baseou em alguma nota manuscrita a margem da coleção que Martius trouxe do Pará e, sem que este tivesse a intenção de distinguíla de sua $R$. brasiliensis. Esta e igualmente a opinião de Eyma (1932). O que não impediu este-autor de descrever a nova espécie $R$.

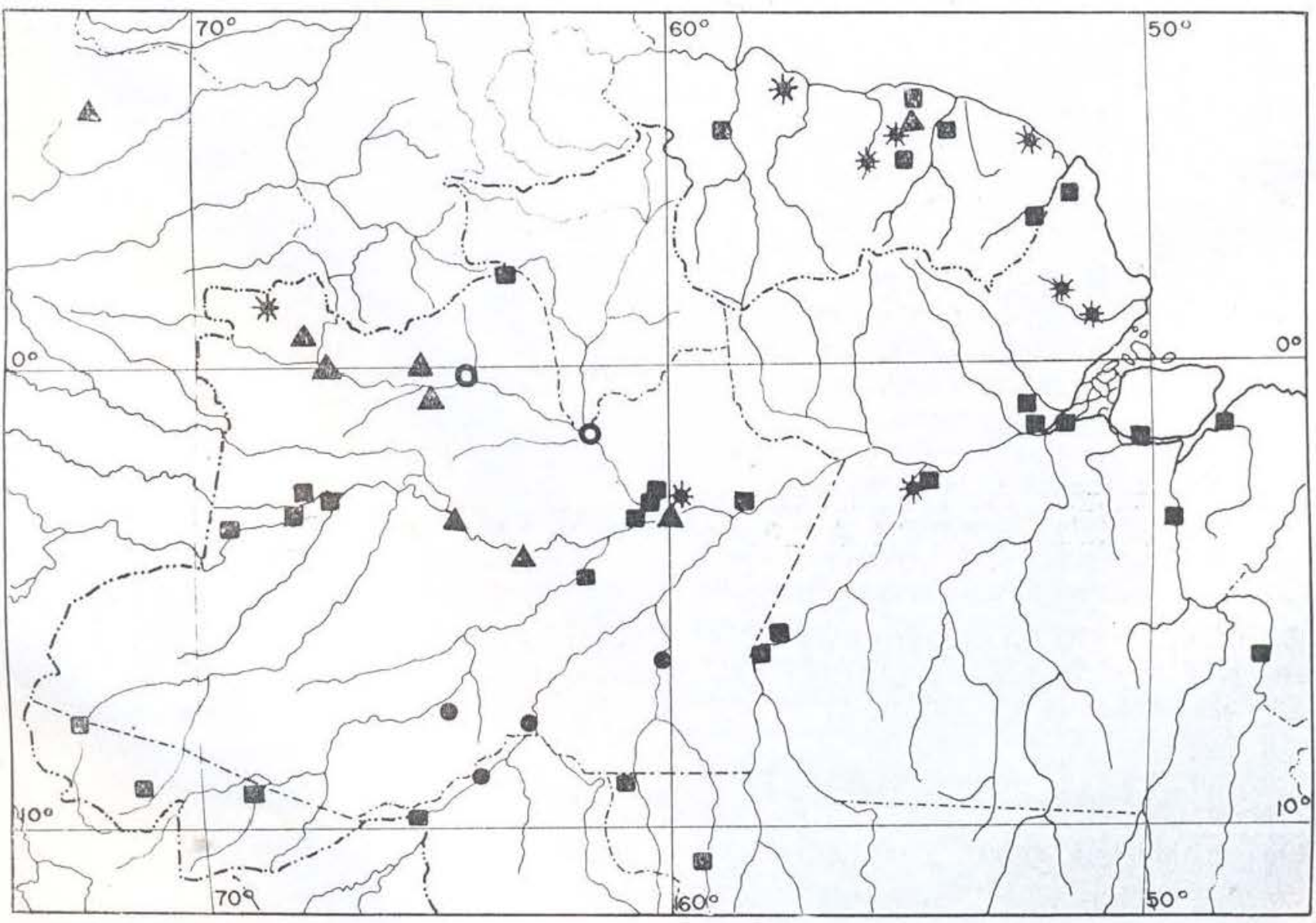

Mapa 1 - Distribuição geográfica: $-\mathbf{R}$. longifolia; $0-\mathbf{R}$, albuquerquei; $-\mathbf{R}$. acuminata; * $-\mathbf{R}$. benthamiana; $\mathbf{A}-\mathbf{R}$, madruno. 


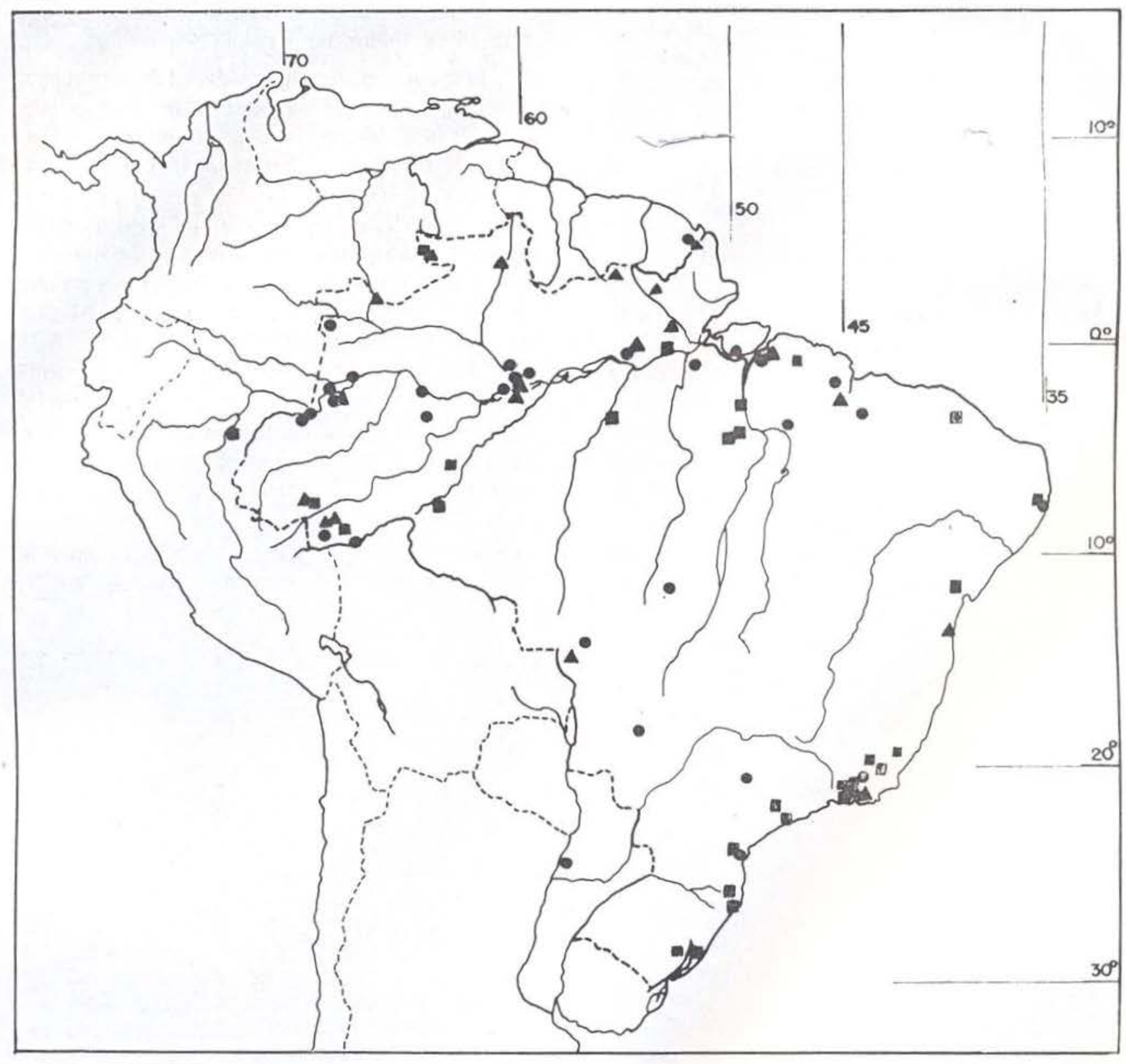

Mapa 2 - Distribuição geográfica: $\mathbf{A}-\mathbf{R}$. macrophylla; $\mathbf{0}-\mathbf{R}$. gardneriana; $\bullet-\mathbf{R}$. brasiliensis.

kappleri, baseado na coleçăo Kappler \& Hostmann 593a, o que ele jamais poderia fazer, por se tratar do holotypus de R. floribunda. Portanto, R. kappleri deve ser considerada uma renomeação ilegítima de R. floribunda. Convém ressaltar que existem duas coleções: Kappler 593a, em Utrecht e, Kappler \& Hostmann 593a (ed. Hohenacker), em Paris. No entanto, trata-se presumivelmente do mesmo espécime, confirmado a opinião de Planchon et Triana (1860). Os mesmos autores consideraram
Verticcilaria rostrata um sinônimo de Rheedia madruno e mencionaram a semelhança entre esta e $R$. acuminata preferincio, entretanto, mantê-las como duas espécies diferentes. Contrariando a opinião de Vesque (1893), que reuniu $R$. acuminata e $R$. madruno em uma só espécie, Pittier (1912) é de opinião que elas sejam consideradas espécies distintas, tendo em vista a diferença existente entre seus frutos. O material por nós estudado mostra, além de frutos, também flores e folhas diferentes 
para $R$. acuminata e $R$. madiruno. Por outro lado Vesque (1893) considerou R. floribunda apenas uma variedade de $R$. acuminata, e, o mesmo autor, baseado em Verticillaria rostrata, fez uma nova comibillação: Rheedia rostrata. De acordo com sua distribuição ao longo da Bacia Amazônica, as coleções identificadas como $R$. acuminata, $R$. floribunda e $R$. rostrata apresentam certa variação nas dimensões e forma da lâmina foliar, facilmente atribuíveis às influências ecológicas. Entretanto, essas coleçōes mantêm constância nas características florais, principalmente no que tange a um típico fendilhamento no estigma e à presença do disco floral concrescido, características essas muito bem ilustradas em Lindeman \& Mennega (1963) e Cavalcante (1972), porém sob identificação errônea (R. kappleri e $R$. benthamiana, respectivamente). Um dos fatores que provocaram sempre confusão entre os diversos autores é o de que nessa espécie, o fruto jovem é bastante diferente do fruto maduro, variando também, a forma do rostro de quase ausente a acentuado. Isso não impede acharem-se na mesma árvore, frutos arredondados ao lado de outros oblongos e semi-rostrados. O pericarpo tende a apresentar-se de verrucoso, nos exemplares da Amazônia Ocidental, a muricado, nos da Amazônia Oriental, $e$, até semi-equinado nos do Suriname. O estudo de material vivo e das coleçőes Spruce 2377, E. Oliveira 1602, E. Oliveira 3539, Pires 3690, Ducke (MG 1912), Cavalcante 2910 e Irvine 48719 permitem acompanhar as semelhanças e variedades desse material e concluir que se trata de uma única espécie.

R. acuminata é a única espécie de Rheedia que apresenta finas linhas longitudinais na lâmina foliar. Seus frutos, embora comestíveis, são pouco apreciados por causa de sua excessiva acidez.

A sua distribuição geográfica está restrita à Hiléia:

Habita as matas de terra firme, sobre latossolos.

Nomes vulgares: bacuri (Acre), bacuri azedo, bacuri de espinhos (Amazonas), bacuri coroa, bacuri de anta, bacuri-pari selvagem (Pará), limãozinho (Mato Grosso), pakoeli e swampoe-pakoeli (Suriname) .
7. Rheedia benthamiana Planchon et Trlana, Ann. Sci. Nat. 4e. sér. 14:320. 1860.

Gafecirria macrophylla "sensu" Bentham in Hook. Lond. Jcur. Bot. 2:369. 1843.

Rheedia macrophylla "sensu" Engler in Fl, Bras. 12 (1) : 460. 1888. "pro parte".

Rheedia macrophylla (Martius) Planchon et Triana var. benthamiana (Planchon et Triana) Vesque in DC, Mon. Phan. 8:500, fig. 5 et 6.1893 .

Rheedia sagotiana Engler, 1.c. : 460 . Holotypus: Guiana Gallica, ad Karouani; Sagot 1122 (V, phototypus IAN).

TYPUS: "Guyane Anglaise"; 1868; Schomburgk 523 (holotypus $\mathrm{P}$, phototypus IAN!).

Árvores de $6-12 \mathrm{~m}$ de altura e $10-20 \mathrm{~cm}$ de diâmetro. Râmulos cilíndricos, fortemente tetrágonos, sulcados e de aspecto reticulado. Folhas: pecíolo de $1,5-2,5 \mathrm{~cm}$ de comprimento e $3-4 \mathrm{~mm}$ de diâmetro, tetrágono sulcado longitudinalmente e extremamente rugoso transversalmente; lâmina de $12-28 \mathrm{~cm}$ de comprimento e $4,5-7 \mathrm{~cm}$ de largura, brilhosa na face ventral e opaca na face dorsal, coriácea, elíptica, raro oboval e assimétrica, base arredondada, ligeiramente atenuada, geralmente assimétrica, ápice arredondado, agudo ou, raro, acuminado, margem revoluta, levemente ondulada; costa supra pouco proeminente, infra muito conspícua, longitudinalmente sulcada, engrossando em direção ao pecíolo, nervação secundária supra pouco proeminente, infra conspícua, apresentando nervuras ascendentes, distanciadas entre si, ca. de $1 \mathrm{~cm}$ que alcançam a margem sob a qual se anastomosam e entre as quais se entremeiam outras (mais numerosas) que alcançam apenas dois terços da lâmina onde se subdividem, reticulação pouco conspícua e concentrada sob a margem. Botões florais pequenos ( $3 \mathrm{~mm}$ de diâmetro), ovaliformes. Flores masculinas: $30-40$, reunidas em fascículos congestơs em râmulos velhos, pedicelos curtos de $8-12 \mathrm{~mm}$; sépalas esverdeadas orbiculares, com $2 \mathrm{~mm}$ de diâmetro; pétalas branco-esverdeadas, ovais, com $5 \mathrm{~mm}$ de altura e $3,5-4 \mathrm{~mm}$ de largura, reflexas após a antese, estames de 15-25. Flores hermafroditas: $10-15$ por fascículo, assentadas sobre um pulvínulo pouco desenvolvido, com pedicelos de $1-2 \mathrm{~cm}$ de com- 
primento; disco arredondado, com $1,5 \mathrm{~mm}$ de altura e $3 \mathrm{~mm}$ de diâmetro; ovário ovóide, com $3 \mathrm{~mm}$ de altura e $2,5 \mathrm{~mm}$ de diâmetro; estigma caliptriforme, lobado, com 2,5mm de diâmetro. Fruto pequeno, esverdeado, com pericarpo verrucoso e com aspecto reticuloso, ovóide, com $1,5-1,8 \mathrm{~cm}$ de comprimento e $1,0-1,3 \mathrm{~cm}$ de diâmetro, ápice agudo, base arredondada.

Floresce de maio a agosto e frutifica de outubro a janerro.

\section{MATERIAL ESTUDADO E DISTRIBUIÇÃO GEOGRÁFICA:}

BRASIL: ESTADO DO PARÁ: Rio Tapajós, Bela Vista; 12-IX-1916; A. Ducke (MG 16488). - Rio Mapuera, ilha Veneza, beira; 03-XII-1907; A. Ducke (MG 9021).

EStAdo do AMAzonas: Manaus, estrada da Forquilha; 17-VII-1961; W. Rodrigues et J. Chagas 2322 (INPA), - Serra do Pirapucu, margem de igarapé; 24-II-1975; M. R. Cordeiro 317 (IAN).

TERRITÓRIO FEDERAL DO AMAPÁ: RiO Araguarí, "between $1^{\circ} 26^{\prime} \mathrm{N}, \quad 51^{\circ} 58^{\prime} \mathrm{W}$ and $1^{\circ}{ }^{\prime} \mathrm{W} "$; 11-IX-1961; J. M. Pires et al, 50854 (MG). - Idem, "vicinity camp 12, $1^{\circ} 11^{\prime} \mathrm{N}, 52^{\circ} 8^{\prime} \mathrm{W}$ "; 30-X-1961; J. M. Pires et al. 51365 (MG, IAN). - Idem; 2-X-1961; J. M. Pires et al. 51442 (MG, IAN). - Idem, Porto Platon; 11-IX-1961; col. NY 50854 (IAN). Idem, Contagem, entre Porto Platon e Serra do Navio; 10-X-1976; N. A. Rosa 1278 (MG). - Margem do rio Cupixi; 27-X-1976; B. G. S. Ribeiro 1576 (MG, INPA).

MATERIAL ADICIONAL :

GUIANA FRANCESA: Cayenne, Itani, Marouni; IX-1961 IFAT 7983 (MG).

SURINAME: Kaboerie, arbor n.0 572; 3-VII-1922 (BW 5911, IAN). - Idem, arbor n. 613; 5-X-1920 (BW 4945, IAN. RB). - Saramacca, Kwakoegron; I-1945 (IAN 38506). - "Ad flumen Coppename, Raleighyallen"; 26-VIII-1920; A. Pulle 325 (RB). - Idem, idem, vicinity Krappa Camp"; 18-VII-1944; B. Maguire 24133 (IAN). - Sectie O; XII-1944 (BW 270, IAN).

GUIANA: Essequibo River, Moraballi Creek, near Bartica, 25-X-1929; N. Y. Sandwith 522 (RB).

Rheedia benthamiana é uma espécie mal conhecida e freciüentemente confundida com R. macrophylla e R. brasiliensis por alguma se- melhança entre o tamanho das folhas ou tipo de nervação, sendo facilmente distinta por seus frutos verrucosos, insignificantes e áci. dos.

Engler considerou R. benthamiana como sinḉnimo de $R$. macrophylla, talvez baseado no aspecto foliar de ambas, quando, em verdade. se trata de duas espécies perfeitamente distintas. A única semelhança entre as folhas dessas duas espécies, está nas dimensões $\epsilon$. assim mesmo, com algumas variações, pois em territórios brasileiros as folhas de $R$. bentha. miana se apresentam às vezes, menores ou mais estreitas que as de plantas ocorrentes no Suriname. O tipo de nervaçăo das folhas de $R$. benthamiana, é irregular e pouco reticulado, sendo bem diferente do apresentado por $R$. macrophylla. Esta exibe densa reticulação sob a margem e nervos secundários, geraimente alcançando as bordas da lâmina foliar. A diferença fundamental entre as duas espécies, indiscutivelmente está nos frutos. R. macrophylla apresenta frutos comestiveis, lisos, com cerca de $5-6 \mathrm{~cm}$ de comprimento e $4,5-5,5 \mathrm{~cm}$ de diâmetro, os maiores entre todas as espécies do çênero. Em contrapartida, R. benthamiana apresenta frutos muito ácidos, pouco apreciados, verrucosos, com comprimento e diâmetro inferiores a $2 \mathrm{~cm}$, dos menores entre as Rheedia. Aliás, esse engano é antigo, pois Bentham (1843) e Choisy (1849) referiram-se a Garcinia macrophylla (basiônimo de Rheedia macrophylla), citando a coleção Schomburgk 523 , que, na realidade, é uma exsicata de $R$. benthamiana. Também Vesque (1893) parece não ter visto os frutos dessas duas espécies, pois fez uma nova combinação de $R$. benthamiana com variedade de $R$. macrophylla. Os próprios autores de $R$. benthamiana, Planchon \& Triana (1860), não conheciam os seus frutos, daí terem evitado de enquadrá-la em uma das cluas secçōes por eles criadas.

Ainda em 1888, Engler parece ter cometido outro engano ac descrever $R$. sagotiana e en. quadrá-la na secção "Eurheedia", pois a coleção Sagot 1182 nada mais é do que uma $R$. benthamiana. Também Vesque $(1860)$ se enganou quando considerou $R$, sagotiana um sinônimo de $R$. macrophylla. 


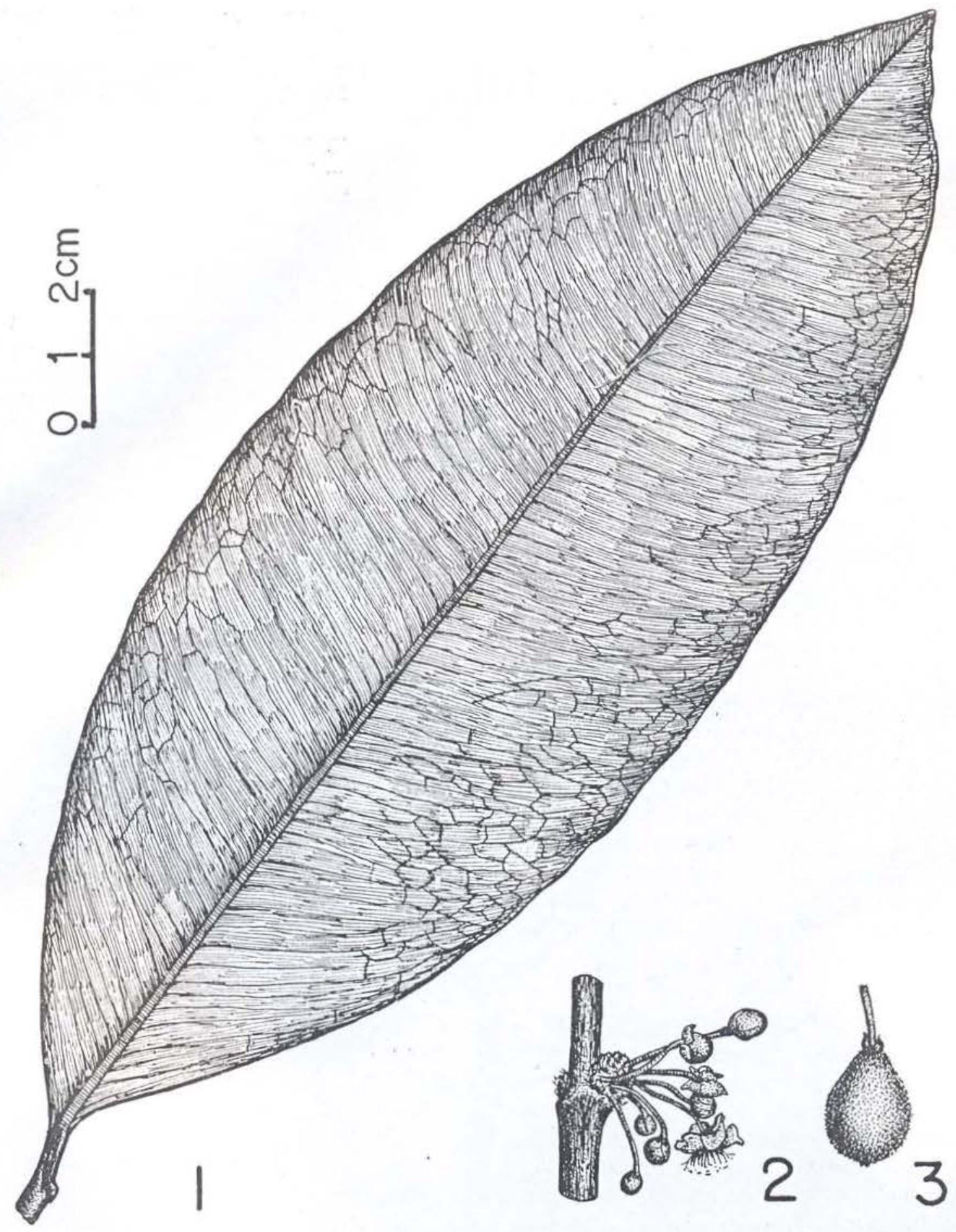

Est, 7 - R, benthamiana: Fig. 1 - Folha (W. Rodrigues et J. Chagas 2322); Fig. 2 - Ramo florifero (J. M. Pires et al, 51442); Fig. 3 - fruto (W. Rodrigues et J. Chagas 2322).

A distribuição geográfica de Rheedia benthamiana está restrita ao norte da Amazônia Oriental.

Nomes vulgares: bacuri (Amazonas), assashi (Guiana) e pakoeli (Suriname).
8. Rheedia madruno (H. B. K.) Planchon et Triana, Ann. Sci. Nat. 4e. sér. 14: 315. 1960.

Calophyllum madruno H.B.K. Nov. Gen, et Sp. $5: 202.1822$. 
Calophyllum acuminatum Willdeneuf, "in shed" (P), non Verticilaria acuminata Ruiz et Pavon.

TYPUS: COLÔMBIA: "Nouvelle-Grenade, dans les vallés du Magdalena et du Cauca, alt. 366-1.000m"; Humboldt et Bonpland 1723 (holotypus P, phototypus IAN!).

Árvores de $6-12 \mathrm{~m}$ de altura e $10-20 \mathrm{~cm}$ de diâmetro com ramos em ângulo obtuso. Râmulos cilíndricos, tetrágonơs em direção ao ápice, sulcados. Folhas: pecíolo alongado, de $15-25 \mathrm{~mm}$ de comprimento e $3 \mathrm{~mm}$ de diâmetro, tetrágono, achatado, profundamente sulcado longitudinalmente e extremamente rugosos transversalmente; lâmina de $12-20 \mathrm{~cm}$ de comprimento e $4-5-13,5 \mathrm{~cm}$ de largura, brilhosa na face ventral e opaca na face dorsal, coriácea, elípitca ou oblonga, raro espatulada, base aguda ou arredondada, ápice agudo ou, às vezes, acuminado, margem revoluta e ondulada, costa supraproeminente e infra muito conspicua, com secção triangular, sendo que na base apresenta as mesmas características do pecíolo, afinando em direção ao ápice, nervação secundária supra e infraproeminente, formando ângulo de $45^{\circ} \mathrm{com}$ a costa, sendo que nervuras mais curtas entremeiam-se com outras que se prolongam até $3 \mathrm{~mm}$ sob a margem, onde se arqueiam e se anastomosam; reticulação irregular, concentrando-se sob a margem. Botões florais ovais. Flores masculinas: $20-40$ por fascículo, pedicelos de $20-30 \mathrm{~mm}$ de comprimento; sépalas esverdeadas ovadas, com $2-3 \mathrm{~mm}$ de altura e 1-2mm de largura; pétalas brancas ovaladas ou oblongas, com $5-7 \mathrm{~mm}$ de altura e 3-3,5mm de largura; estames de 25-30; disco cônico muricado. Flores hermafroditas: 5-10 por fascículo, disco de $2 \mathrm{~mm}$ de altura e $3 \mathrm{~mm}$ de diâmetro, ovário ovóide com $5,5 \mathrm{~mm}$ de altura e $3,5 \mathrm{~mm}$ de diâmetro, coroado por um estigma caliptriforme com ca. de $1,5 \mathrm{~mm}$ de altura e $4 \mathrm{~mm}$ de diâmetro. Fruto muricado, amarelo, ovóide, de 5,5-6-5cm de comprimento e $4-5 \mathrm{~cm}$ de diâmetro, ápice sem rostro, base arredondada, com restos do perianto e androceu.

Floresce de maio a agosto e frutifica de outubro a fevereiro.

MATERIAL ESTUDADO E DISTRIBUIÇÃO GEOGRÁFICA:

BRASIL: estado do PARÁ: Gurupá; 23-IX-1916; A. Ducke (MG 16529). estado do amazonas: Manaus; 5-IV-1975, P. Cavalcante (Carp. MG 1808). - Idem; km 9 da BR-17; 14-IX-1955; Chagas (MG 21.207, INPA) 1943. - Alto rio Negro, abaixo da boca do rio Waupis, ilha Cumatú; 17-II 1959; W. Rodrigues 901 (INPA). - Lago do Janauari, margem direita do rio Negro, W. Rodrigues \& J. Lima 2481 (MG, INPA). - "Rio Negro between ilha da Silva e Tapuruquara, black water flooded river margin", 15-X-1971, G. T. Prance et al. 15268 (INPA). - Coari, lago do Coari, 23-II-1972, Byron et al. 497 (INPA). - Tefé, beira do lago; 28-II-1972; Byron et al. 578 (MG, INPA). - Idem, Nogueira; 26-X-1972; M. Dantas 12380 (INPA).

MATERIAL ADICIONAL :

COLOMBIA: Departamento Boyacá: El Guira, "between Barranca de Upia and Mani, alt. 250m; 14-II-1939, O. Haught 2607 (IAN).

SURINAME: Zanderij I, arbor 103; 10-XI-1915; BW 1261 (RB).

Rheedia madruno é encontrada em estado semi-silvestre na Amazônia Brasileira, enquan. to que na Colômbia, é encontrada em cuitivos dơmésticos. Possui ótimo sabor e é muito apreciada.

Está restrita à Amazônia Oriental e Suriname.

Habita as matas de terra firme, em geral sobre solos arenosos.

Nomes vulgares: "bacuri", "bacuri verdadeiro" (AM) (näo confundir com o legitimo que é Platonia insignis), "madrõno" (Venezuela), "naranjuelo" (Colômbia).

\section{AgRAdECIMENTOS}

Ao Dr. Sylvio Panizza, professor do Departamento de Botânica do Instituto de Biociências (IB), da Universidade de São Paulo (USP), orientador, pela revisão crítica do texto da tese, pela amizade e incentivo em todas as horas.

Ao Dr. Ghillean T. Prance, do New York Botanical Garden e INPA, por sua leitura, úteis sugestões e interesse em relação à publicaçâa desta pesquisa. 


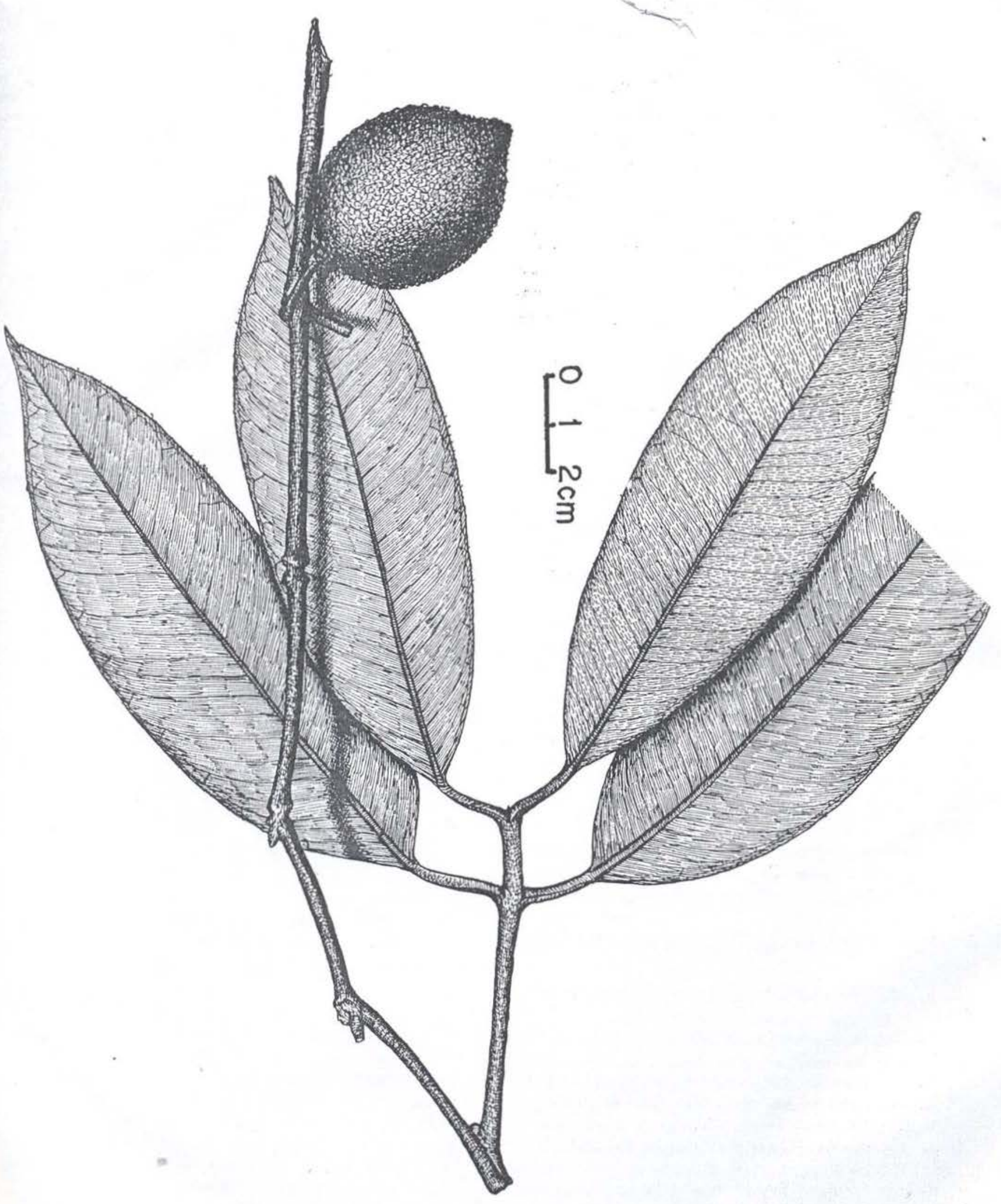

Est. 8 - R. madruno: Fig. 1 - ramo florifero (W. Rodrigues et S. Lima 2481). 
Ao Conselho Nacional de Desenvolvimento Científico e Tecnológico (CNPp) pela bolsa usufruída durante a preparação deste trabalho (1973-1975) .

Aos curadores dos herbários que emprestaram material para nosso estudo.

As Srtas. Helena Silveira e Regina Silva bibliotecárias do Museu Goeldi pela revisão e normalização completa das citações bibliográficas e ao Dr. William Overal, entơmólogo do M. Goeldi, pela revisão do "summary". Ao Sr. Raphael F. Alvarez, desenhista do Departamento de Botânica do Museu Goeldi, pelo esmero na confecção das estampas que ilustram esta revisão.

A todas as pessoas que direta ou indiretamente colaboraram para a realização desta pesquisa.

Finalmente, mas não em último lugar, queremos registrar a nossa profunda gratidão ao Prof. Dr. Warwick Estevam Kerr, Diretor do Instituto Nacional de Pesquisas da Amazônia pelo seu interesse, constante incentivo e efetivo apoio que foram fundamentais na realização deste trabalho.

\section{SUMMARY}

This paper presents a revision of the brazilian species of Rheedia L. (Guttiferae), a typical genus of the tropical American and Madagascan flora, with edible fruits, oil-containing seeds and wood having restricted uses. The remarkable variation of some morphological aspects was not fully described, and the structure of the fruit was not previously completely studied.

The confusing synonymy that has subsequently developed is further discussed herein.

The geographycal distribuition and phenology are also studied here.

Nine conclusions have drawn as a result of this research: found:

1. In Brazil eight valid species of Rheedia are

R. longifolia Planchon et Triana

R. albuquerquei van den Berg

R. macrophylla (Martius) Planchon et Triana

R. gardneriana Miers ex Planchon et Triana

R. brasiliensis (Martius) Planchon et Triana

R. acuminata (Ruiz et Pavon) Planchon et Triana

R. benthamiana Planchon et Triana

R. madruno (H.B.K.) Planchon et Triana

2. With the exception of $\mathbf{R}$. benthamiana all these species have edible fruits.
3. R. benthamiana is a valid species and not a synonym of $\mathbf{R}$. macrophylla.

4. R. sagotiana must be considered a synonym of $\mathbf{R}$. benthamiana.

5. R. caliptrata Planchon et Triana, R. spruceana Engler, R. spruceana var. cuneata Engler, R. tenuifolia Engler, R. gardneriana var. parvifolia Engler and R. gardneriana var. glaziovii Engler must be considered synonyms of $\mathbf{R}$. gardneriana.

6. R. floribunda - (Miquel) Planchon et Triana, R. acuminata var. floribunda (Miquel) Vesque, R. rostrata Miers ex Vesque and $\mathbf{R}$. kappleri Eyma must be considered synonyms of R. acuminata.

7. The greatest range of ocurrence in Brazil was recorded for $\mathbf{R}$. gardneriana, $\mathbf{R}$. brasiliensis and R. macrophylla. The latter two species share also the largest geographical distribution in the Amazonian region, but not as great as $\mathbf{R}$. acuminata.

8. R. Iongifolia is an endemic species in the geographycal region belonging to the Purus and Madeira-Mamoré River Basins, in Brazilian Amazonia.

9. R. albuquerquei is an endemic species in the geographical region belonging to rio Negro Basin, also in Brazilian Amazonia.

\section{BIBLIOGRAFIA}

ANGELY, J.

1965 - Flora analítica do Paraná. São Paulo, Phyton., 728 p. (Coleção Saint Hilaire, 7), p. 453 .

AubLet, J.F.

1775 - Historie des Plantes de la Guiane Française... Paris, Didot Jeune. v. 1 p. 532.

Bentham, G.

1843 - Contribution toward a Flora of South America. Lond. J. Bot., 2:369.

Cavalcante, P.B.

1972 - Frutas comestíveis da Amazônia - I. Publ Avul. Mus. Pa. Emílio Goeldi, Belém, $17: 49-50$, est. 20.

Chodat, R. \& Hassler, E.

1903 - Plantae Hassierianae. Bull. Herb. Boissier, Geneve, 2(3) : 1125-1126.

ChorsY, J.D.

1924 - Guttiferae. In: DE CANDOLLE, A. P. Prodromus Systematis Naturais Regni Vegetabilis. Genève, Treuttel \& Wurtz. v. 1, p. $560-64$.

1849 - Guttiferae de l'Inde. Mem. Soc. Phys. Hist. Nat., Genève, $12: 33-47$, tab. 5 .

ENGLER, A.

1888 - Guttiferae. In: MARTIUS, C.F.P. von Flora Brasiliensis, Monachii. Frid. Freischer. v. 12 t. 1 p. $458-65$, tab.

1895 - Guttiferae. In: ENGLER, A. PRANTI, K. Die Naturlichen Pflanzenfamilien. Leipzig, Wilhelm Engelmann. v. 3, Part. 6, p. $229-230$. 
EYMA, P.J.

1932 - New and critical Polygonaceae, Guttiferae and Lecythidaceae from Surinam. Meded. bot. Lab. Herb. Rijks - Univ., Utrecht, 4:24. 43, fig. 5-6.

Humboldt, F.W.H.A. von; Bonpland, A.J.A. \& KUNTH, K.S.

1821 - Nova Genera et Species Plantarum, Paris, N. Maze Libraire, v. 5, p. 156.

KLEIN, R.M.

1872 - Arvores nativas da floresta subtropical do Alto Uruguai. Sellowia, Itajai, 24(24): 9-62.

Lanjouw, J. \& Stafleu, F.A.

1959 - Index Herbariorum. I-The Herbaria of the world. 4. ed. Utrecht, International Association for Plant Taxonomy, $249 \mathrm{p}$.

Le Cointe, $\mathrm{P}$.

1947 - Amazônia brasileira III - Arvores e plantas úteis (indigenas e aclimadas), 2. ed. São Paulo, Ed, Nacional, p $\quad 59-60$

Lindeman, J.C. \& Mennega, A.M.W.

1963 - Bomenboack voor Suriname - "Herkenning van Surinamse houtsoorten aan hout vegetative kenmerken". Meded. bot. Lab. Herb. Rijks. - Univ., Utrecht, 200-153-154, fig. 26-27.

LINDMAN, C.A.M.

1906 - A vegetação do Rio Grande do Sul, (Bra. sil austral). Porto Alegre, Livraria Universal, XII, 356 il. 2 mapas.

Linnaeus, C.

1735 - Systema naturae... Leiden, p. 1356.

1753 - Species plantarum... Stockholm, v. 2, p. 1193

MACHADO, O.

1954 - Botânica - Plantas do Brasil Central (Cortribuição ao conhecimento da flora do Brasil). Rio de Janeiro, Imprensa Nacicnal, p. 33.

MAriz, G.

1974 - Guttiferae of Pernambuco (Brasil). Candollea, Genéve, $29:$ 7-11.

MARTIUS, C.F. VON

1841 - Beiblat zur Flora. Jena, s, ed., v. 24. t. 2 p. $33-4$.

MELCHIR, $\mathrm{H}$.

1964 - A Engler's Syllabus der Pflanzenfamilien, Berlin, Gebruder Borntraeger v. 2 p. 170-172.

Miers, J.

1853 - Description of a new genus of plants of South America. Trans. Linn. Soc. Lond, $21: 249$.

MiQuel, F.A.G.

1850 - Stirpes Surinamensis Selectae. Lugduni Batavorum, Arnz \& Soc, p. 88-90.
PERSOON, C.H.

1807 - Synopsis Plantarum... Parisiis, s. ed. v. 2, p. 73 .

PitTiER, H.

1912 - New and noteworthy plants from Colombia and Central America - 3. Contr. U. S. nat. Herb.. Washington, 13(12) : 453-456.

Planchon, J.E. \& Triana, J.

1860 - Memoire sur la Familie des Guttiferes. In: Ann. Sci, nat., Paris, 14(4) : 22-325.

Plumier, C.

1703 - Nova plantarum Ámericanorum genera. Parisiis, Boudot. p. 45.

1755-60 - Genera plantarum Americanorum. Pa. risiis, p. 255 , tab. 157 .

Pulle, A.

1806 - An Enumeration of the vascular plants Known from Surinam, together with their distribution and synonymi. Leiden, E.J. Brill. p. 308 .

RAMво, B.

1954 - Análise histórica da Flora de Porto Alegre. Sellowia, Itajaí, $6: 9-112$.

1954 - História da Flora do litoral riograndense. Sellowia, Itajaí, $6: 113-172$.

RODRIGUES, J.B

1874 - Hortus Fluminensis. Río de Janeiro, Typ. Leuzinger. p. 60.

1905 - Mbaé kaá Tapyyeté Enoyndaua ou Bo. tânica da nomenclatura indigena; memória apresentada ao $3 .^{\circ}$ Congresso Científico Latino Americano. Rio de Janeiro, Imprensa Nacional. v. 1 ,

Ruiz, H.L. \& PAvon, J.A.P.G.

1794 - Prodromus Florae Peruviana et Chilen. sis... Madrid, s. ed. p. 81. tab. 15.

SAmpaio, T.

1970 - O Tupi na geografia nacional. 4. ed. São Paulo, USP., 304 p.

STAFLEU ET ALII.

1972 - International Code of Botanical No. menclature; adapted by the 11 th International Botanical Congress, Seattle, August 1969, Utrecht. p. 21.

STANDLEY, P.C. \& STEYERMARK, J.A.

1944 - Studies of Central American Plants IX. Fieldiana Bot., Chicago, 23(2): 65 .

Standley, P.C. \& Wilitims, L.O.

1961 - Flora of Guatemala. Fieldiana Bot., Chicago, 24(7) : 55-56.

Stradelli, E.

1928 - Vocabulário da lingua geral portugueznheêngatu e nheêngatu-portuguez, procedidos de um esboço de grammatica nheêngaumbuèsáua mirê e seguidos de contos em língua geral nheêngatu poranduua. In: R. Inst. Hist. Geogr. Bras., Rio de Janeiro, 104(158): 53. 
VeSQUE, J.

1889 - Epharmosis. Vincennes, s. ed., v. 2. p. 24, tab. 72 .

1893 - Guttiferae. In: CANDOLLE, Alphonse de \& CANDOLLE, Casimir. Monographiae phanerogamarum, prodromi nunc continuatro, nunc revision. Parisú, Iumptibus G. Masson. v. 8. p. 64 .
WILLIS, J

1973 - A dictionary of flowering plants and ferns, 8, ed. rev. Cambridge, University Press. p. 516-989.

(Aceito para publicação em 11/08/78)

\section{LISTA DE COLETORES CITADOS}

- ARCHER, W.A.

7544 - R. macrophylla

7879 - R. macrophylla

- BERG, C.C.

P. $19731-R$. acuminata

- BLACK, G.A.

47-1214 - R. brasiliensis

- BLAK, G.A. et al.

$9852-R$. acuminata

- BRADE, A.C.

$7906-$ R. gardneriana

- BONDAR, G.

2271 - R. gardneriana

- BYRON

$6782-R$. albuquerquei

- BYRON et al.

497 - R. madruno

578 - R. madruno

- CAMPBELL, D.G. et al.

P. $20866-R$. acuminata

- CAVALCANTE, P.

311 - R. macrophylla

2375 - R. macrophylla

$2769-R$. acuminata

$2770-R$. brasiliensis

2910 - R. acuminata

Carp. MG 1461 - R. macrophylla

Carp. MG 1808 - R. madruno

- CHAGAS, J.

MG $21196-R$. acuminata

MG $21207-R$. madruno

MG $48035-R$. brasiliensis

- costa, M. da

480 - R. macrophylla

- CONSTANTINO, D.

RB 21323 - R. brasiliensis

- CORDEIRO, M.R.

$317-\mathrm{R}$. benthamiana

- DANTAS, M.

12380 - R. madruno

- DUBOIS, J.

INPA 17041 - R. macrophylla

- DUCKE, A.

$714-\mathrm{R}$. acuminata

783 - R. macrophylla
1570 . - R. acuminata

1571 - R. acuminata

$1572-R$. brasiliensis

$1573-R$. brasiliensis

MG $7396-$ R. acuminata

MG $7639-R$. brasiliensis

MG $9021-R$. benthamiana

MG $15.296-R$. brasiliensis

MG $16.475-R$. gardneriana

MG $16.488-R$, benthamiana

MG $16.529-R$. madruno

MG $16.672-R$. brasiliensis

MG $16.957-R$. macrophylla

MG $17.268-R$. acuminata

Carp. MG $615-R$. acuminata

Carp. MG $623-\mathrm{R}$. macrophylla

- DUCKE, A. et KUHLMANN

MG $49528-R$. gardneriana

- DIONISIO

MG $48.036-R$, acuminata

- DUTRA, J.

$\mathrm{R}-79.263-\mathrm{R}$. gardneriana

- FREIRE - ALEMAOO et CYSNEIROS, M

$180-\mathrm{R}$. gardneriana

$\mathrm{R}-79.141-\mathrm{R}$. gardneriana

- FROES, R.L.

$22.702-\mathrm{R}$. albuquerquei

$23.389-R$. gardneriana

$23.709-R$. brasiliensis

$23.710-R$. macrophylla

$23.773-\mathrm{R}$. acuminata

$25.895-R$. macrophylla

$26.142-R$. brasiliensis

$26.460-R$. longifolia

$29.592-R$. brasiliensis

$31.987-R$. gardneriana

- FROES, R.L. \& BLACK, G.A.

$24.603-R$. gardneriana

IAN $51.073-R$. gardneriana

- GLAZIOU

$7.527-R$. gardneriana

$13.579-R$. gardneriana

$15.858-R$. macrophylla

$18.154-R$. brasiliensis

$18.155-R$. gardneriana

- GUEDES, M.

MG $2171-R$. acuminata 
- GOELDI, A.

MG $4232-R$. gardneriana Carp. MG $623-\mathrm{R}$. acuminata

- HARLEY, R.M. \& SOUSA, R. $11.146-R$. brasiliensis

- HAUGHT, $\mathrm{O}$.

2607 - R. madruno

- HASSLER, E.

RB $7.038-R$. brasiliensis

- HATSCHBACH

1049 - R. brasiliensis

- HOEHNE

906 - R. macrophylla

923 - R. macrophylla

4.351 a4 - R. brasiliensis

4.356 a7 - R. brasiliensis

$8.358-R$. gardneriana

SP $1.882-R$. gardneriana

SP $24.298-R$. gardneriana

SP $24.334-R$. gardneriana

SP $27.156-R$. gardneriana

SPF $5594-R$. gardneriana

- HUBER, $\mathrm{S}$.

MG $9351-R$. macrophylla

- HUNT, D.R. \& RAMOS, U.F.

$5965-R$. brasiliensis

INSTITUTO AGRONOMICO DC NORTE

(atual CPATU).

IAN $38.498 \mathrm{a}-\mathrm{R}$. acuminata

- IFAT (Instituto Florestal)

7983 - R. benthamiana

- IRWIN, H.S. et al.

48.295 - R. macrophylla

48.296 - R. macrophylla

$48.429-$ R. acuminata

$48.719-R$. acuminata

- KILLIP, E.P. \& SMITH, A.C. RB $21.801-R$. gardneriana

- KRUKOFF, B.A.

$4765-$ R. macrophylla

4919 - R. acuminata

$5102-R$. gardneriana

$5473-R$. acuminata

- KUHLMANN, J.G.

284 - $R$, brasiliensis

$706-R$. brasiliensis

2018 - R. acuminata

RB $21.324-R$. brasiliensis

- KULMANN, M.

$3132-R$. gardneriana

$3676-R$. brasiliensis

- LANJOW, J. \& LINDEMANN, J.C.

$517-\mathrm{R}$. acuminata

- LE COINTE, P.

MG $7046-R$. brastliensis

- LIMA, A.

48-61 - R. macrophilla

- LIMA, D.A.

1365 - R. gardneriana
- LIMA, F.Q.

MG $2315-R$. brasiliensis

- LISBOA, P.L.

$15-R$. brasiliensis

- LISBOA, P.L. et al. $476-\mathrm{R}$. acuminata

- LOEFGREN et EDWAL SP $28262-R$. gardneriana

- LOUREIRO, A. et al. MG 48072 - R. acıminata

- LUIZ MG $48034-R$, brasiliensis

- MAAS, P.J.M. et al. P12759 - R. longifolia

- MAGUIRE, B. 23373 - R. acuminata 24133 - R. benthamiana

- MARINHO, L.R. $243-R$, acuminata

- MARIZ, G. 330 - R. macrophylla $650-\mathrm{R}$. gardneriana s/n (U.F.Pe.) - R. brasiliensis

- MEXIA, Y. 5297 - R. gardneriana 5323 - R. gardneriana

- MONTEIRO, O.P. INPA $53470-R$. gardneriana

- MUSEU GOELDI (MG) 9612 - R. acuminata Carp. $1461-$ R. macrophylla

- MUSEU NACIONAL (R) 78967 - R. gardneriana 79148 - R. gardneriana $136.102-R$. gardneriana

- NUNES, G.M. R50 - R. gardneriana

- OLIVEIRA, E. 1602 - R. acuminata $2976-R$. acuminata $3529-R$. acuminata $5939-\mathrm{R}$. acuminata

- PENA, B.S. IAN $146.512-R$. brasiliensis

- PEREIRA, E. et al. $3571-R$. brasiliensis 4173 - $R$. brasiliensis

- PIRES, J.M. 3690 - R. acuminata 4025 - R. acuminata 4047 - R. acuminata 8219 - R. mecrophylla MG $51858-R$. acuminata MG $47.411-R$. brasiliensis

- PIRES, J.M. et al. 4985 - R. macrophylla 10966 - R. acuminata $13740-R$. brasiliensis $50854-R$. benthamiana 
51365 - R. benthamiana $51442-R$. benthamiana $51569-R$. benthamiana

- PIRES, J.M. et BELEM, R.P. 12299 - R. gardneriana. $12308-R$. gardneriana

- PIRES, J.M. et BLACK, G.A. 1770a - R. brasiliensis

- PIRES, J.M. et ROSA, N.A. 13279 - R. longifolia

- PIRES, J.M. et SILVA, N.T. 10277 - R. acuminata $10541-R$. acuminata $10685-R$. acuminata $11128-\mathrm{R}$. macrophylla

- PIRES, O. 243 - R. macrophylla

- PRANCE, G.T. 1713 - R. acuminata

- PRANCE, G.T. et al. 2793 - R. acuminata 2981 - R. acuminata $3190-R$. brasiliensis 4314 - R. macrophylla $4592-R$. macrophylla $5649-\mathrm{R}$. longifolia $6176-R$. gardneriana $6230-R$. longifolia 7778 - R. macrophylla 7874 - R. macrophylla 7944 - R. macrophylla $10.293-R$. acuminata $10494-R$. gardneriana 10653 - R. macrophylla $14248-R$. longifolia 15268 - R. madruno $16760-R$. brasiliensis $16801-R$. brasiliensis $17453-R$. acuminata 18.311 - R. acuminata 23.908 - R. gardneriana

- PRANCE, G.T. et PENNINGTON, T.D 1997 - R. macrophylla

- PULLE, A. $325-\mathrm{R}$. benthamiana

- REGNELL $1528-R$. gardneriana

- REITZ 1917 - R. gardneriana

- RIJKSHERBARIUM (U) BW $204-R$. acuminata BW $1261-R$. madruno BW 1618 - R. acuminata BW 1818 - R. acuminata BW $1999-R$. acuminata BW $3907-R$. macrophylla BW $6569-$ R. macrophylla

- RIBEIRO, B.G.S. $1576-R$. benthamiana
- RODRIGUES, R.S. MG $4050-R$. gardneriana

- RODRIGUES, W. $901-$ R. madruno 1611 - R. acuminata $9141-R$, acuminata

- R.ODRIGUES, W. et CHAGAS, J. 2322 - R. benthamiana

- RODRIGUES, W. et COELHO, L. $8350-R$. albuquerquei

- RODRIGUES, W. et LIMA, J. 2481 - R. madruno

- RODRIGUES, W. et OSMARINO 8217 - R. acuminata

- ROSA, N.A. 1278 - R. benthamiana

- ROSA, N.A. et al. $159-R$. acuminata

- RÖSA, N.A. et CARDOSO, O. 2539 - R, brasiliensis

- ROSA, N.A. et CORDEIRO, M.R. $1602-R$. macrophylla

- SALDANHA, J. de 358 - R. acuminata

- SANDWITH, N.Y. $522-\mathrm{R}$. benthamiana

- SCHULTES, R.E. $24535-R$. albuquerquei

- SCHWACKE 6488 - R. brasiliensis

- SILVA, M. $749-\mathrm{R}$. brasiliensis 947 - R. acuminata 1358 - R, acuminata.

- SILVA, N.T. $23-R$. acuminata $895-R$. acuminata $1660-R$. macrophylla $2201-R$. acuminata 3386 - R. acuminata

- SMITH, A.C. $3402-R$. macrophylla

- SPRUCE, R. $1744-R$. brasiliensis 2377 - R. brasiliensis $2441-R$. longifolia (TYPUS)

- TAVARES, $\mathbf{S}$. 547 - R. gardneriana

- VAN DEN BERG, M.E. $95-\mathrm{R}$. macrophylla $96-\mathrm{R}$. acuminata - VELOSO, H.P. $9-$ R. gardneriana $291-R$. gardneriana 816 - R. macrophylla

- VIDAL, J. $5310-R$. gardneriana 5612 - R. brasiliensis 